4

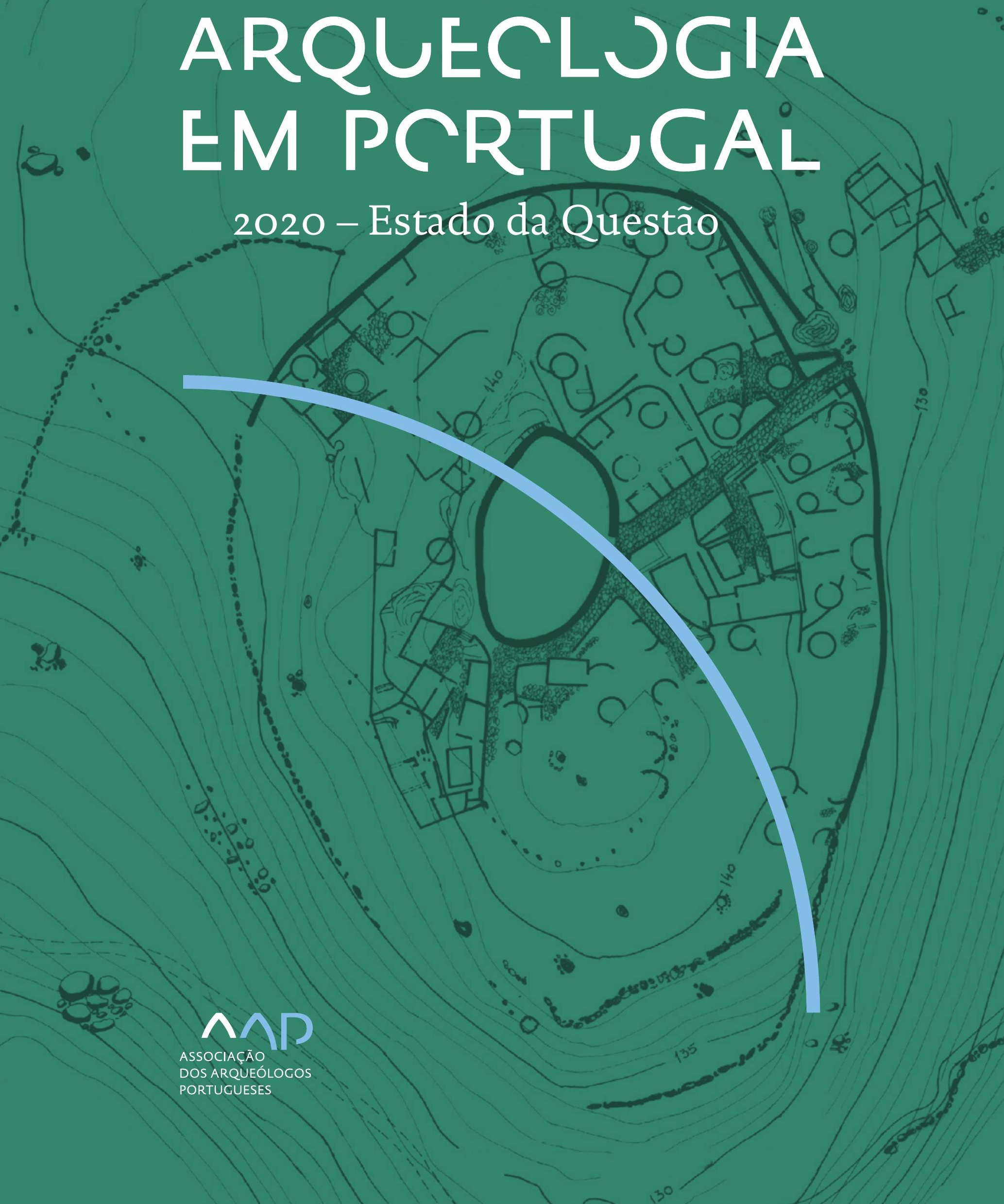


Coordenação editorial: José Morais Arnaud, César Neves e Andrea Martins Design gráfico: Flatland Design

AAP - ISBN: 978-972-9451-89-8

CITCEM - ISBN: 978-989-8970-25-1

Associação dos Arqueólogos Portugueses e CITCEM

Lisboa, 2020

O conteúdo dos artigos é da inteira responsabilidade dos autores. Sendo assim a Associação dos Arqueólogos Portugueses declina qualquer responsabilidade por eventuais equívocos ou questões de ordem ética e legal.

Desenho de capa:

Planta do castro de Monte Mozinho (Museu Municipal de Penafiel).

\section{$\hat{\wedge} \mathrm{P}$}

DOS ARQUEÓLOGOS PORTUGUESES

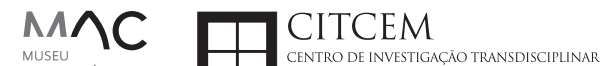
MUSEU
ARQUELLÓGICO
DO CARMO
U.PORTO

FLUP FACULDADE DE LETRAS
UNIVERSIDADE DO PORTO

Apoio

EC para a Ciência 


\section{Índice}

15 Prefácio

José Morais Arnaud

\section{Historiografia e Teoria}

17 Território, comunidade, memória e emoção: a contribuição da história da arqueologia (algumas primeiras e breves reflexões)

Ana Cristina Martins

25 Como descolonizar a arqueologia portuguesa?

Rui Gomes Coelho

41 Arqueologia e Modernidade: uma revisitação pessoal e breve de alguns aspetos da obra homónima de Julian Thomas de 2004

Vítor Oliveira Jorge

57 Dados para a História das Mulheres na Arqueologia portuguesa, dos finais do século XIX aos inícios do século XX: números, nomes e tabelas

Filipa Dimas / Mariana Diniz

73 Retractos da arqueologia portuguesa na imprensa: (in)visibilidades no feminino

Catarina Costeira / Elsa Luís

85 Arqueologia e Arqueólogos no Norte de Portugal Jacinta Bugalhão

101 Vieira Guimarães (1864-1939) e a arqueologia em Tomar: uma abordagem sobre o território e as gentes

João Amendoeira Peixoto / Ana Cristina Martins

115 Os memoráveis? A arqueologia algarvia na imprensa nacional e regional na presente centúria (2001-2019): características, visões do(s) passado(s) e a arqueologia

enquanto marca

Frederico Agosto / João Silva

129 A Evolução da Arqueologia Urbana e a Valorização Patrimonial no Barlavento Algarvio: Os casos de Portimão e Silves

Artur Mateus / Diogo Varandas / Rafael Boavida

\section{Gestão, Valorização e Salvaguarda do Património}

145 O Caderno Reivindicativo e as condições de trabalho em Arqueologia Miguel Rocha / Liliana Matias Carvalho / Regis Barbosa / Mauro Correia / Sara Simões / Jacinta Bugalhão / Sara Brito / Liliana Veríssimo Carvalho / Richard Peace / Pedro Peça / Cézer Santos

155 Os Estudos de Impacte Patrimonial como elemento para uma estratégia sustentável de minimização de impactes no âmbito de reconversões agrícolas Tiago do Pereiro

165 Salvaguarda de Património arqueológico em operações florestais: gestão e sensibilização Filipa Bragança / Gertrudes Zambujo / Sandra Lourenço / Belém Paiva / Carlos Banha / Frederico Tatá Regala / Helena Moura / Jacinta Bugalhão / João Marques / José Correia / Pedro Faria / Samuel Melro

179 Os valores do Património: uma investigação sobre os Sítios Pré-históricos de Arte Rupestre do Vale do Rio Côa e de Siega Verde José Paulo Francisco 
189 Conjugando recursos arqueológicos e naturais para potenciar as visitas ao Geoparque Litoral de Viana do Castelo (Noroeste de Portugal)

Hugo A. Sampaio / Ana M.S. Bettencourt / Susana Marinho / Ricardo Carvalhido

203 Áreas de Potencial Arqueológico na Região do Médio Tejo: Modelo Espacial Preditivo Rita Ferreira Anastácio / Ana Filipa Martins / Luiz Oosterbeek

223 Património Arqueológico e Gestão Territorial: O contributo da Arqueologia para a revisão do PDM de Avis

Ana Cristina Ribeiro

237 A coleção arqueológica do extinto Museu Municipal do Porto - Origens, Percursos e Estudos

Sónia Couto

251 Valpaços - uma nova carta arqueológica

Pedro Pereira / Maria de Fátima Casares Machado

263 Arqueologia na Cidade de Peniche

Adriano Constantino / Luís Rendeiro

273 Arqueologia Urbana: a cidade de Lagos como caso de Estudo Cátia Neto

285 Estratégias de promoção do património cultural subaquático nos Açores. O caso da ilha do Faial

José Luís Neto / José Bettencourt / Luís Borges / Pedro Parreira

297 Carta Arqueológica da Cidade Velha: Uma primeira abordagem

Jaylson Monteiro / Nireide Tavares / Sara da Veiga / Claudino Ramos / Edson Brito /

Carlos Carvalho / Francisco Moreira / Adalberto Tavares

311 Antropologia Virtual: novas metodologias para a análise morfológica e funcional Ricardo Miguel Godinho / Célia Gonçalves

\section{Didáctica da Arqueologia}

327 Como os projetos de Arqueologia podem contribuir para uma comunidade culturalmente mais consciente Alexandra Figueiredo / Claúdio Monteiro / Adolfo Silveira / Ricardo Lopes

337 Educação Patrimonial - Um cidadão esclarecido é um cidadão ativo! Ana Paula Almeida

351 A aproximação da Arqueologia à sala de aula: um caso de estudo no $3^{\circ}$ ciclo do Ensino Básico Luís Serrão Gil

363 Arqueologia 3.o - Pensar e comunicar a Arqueologia para um futuro sustentável Mónica Rolo

377 “Conversa de Arqueólogos" - Divulgar a Arqueologia em tempos de Pandemia Diogo Teixeira Dias

389 Escola Profissional de Arqueologia: desafios e oportunidades Susana Nunes / Dulcineia Pinto / Júlia Silva / Ana Mascarenhas

399 Os Museus de Arqueologia e os Jovens: a oferta educativa para o público adolescente Beatriz Correia Barata / Leonor Medeiros

411 O museu universitário como mediador entre a ciência e a sociedade: o exemplo da secção de arqueologia no Museu de História Natural e da Ciência da Universidade do Porto (MHNC-UP)

Rita Gaspar 
421 Museu de Lanifícios: Real Fábrica de Panos. Atividades no âmbito da Arqueologia Beatriz Correia Barata / Rita Salvado

427 Arqueologia Pública e o caso da localidade da Mata (Torres Novas) Cláudia Manso / Ana Rita Ferreira / Cristiana Ferreira / Vanessa Cardoso Antunes

431 Do sítio arqueológico ao museu: um percurso (também) didático Lídia Fernandes

447 Estão todos convidados para a Festa! E para dançar também... O projecto do Serviço Educativo do Museu Arqueológico do Carmo na $5^{\underline{a}}$ Edição da Festa da Arqueologia Rita Pires dos Santos

459 O “Clã de Carenque”, um projeto didático de arqueologia Eduardo Gonzalez Rocha

469 Mediação cultural: peixe que puxa carroça nas Ruínas Romanas de Troia Inês Vaz Pinto / Ana Patrícia Magalhães / Patrícia Brum / Filipa Santos

481 Didática Arqueológica, experiências do Projeto Mértola Vila Museu Maria de Fátima Palma / Clara Rodrigues / Susana Gómez / Lígia Rafael

\section{Arte Rupestre}

497 Os inventários de arte rupestre em Portugal Mila Simões de Abreu

513 O projeto FIRST-ART - conservação, documentação e gestão das primeiras manifestações de arte rupestre no Sudoeste da Península Ibérica: as grutas do Escoural e Maltravieso Sara Garcês / Hipólito Collado / José Julio García Arranz / Luiz Oosterbeek / António Carlos Silva / Pierluigi Rosina / Hugo Gomes / Anabela Borralheiro Pereira / George Nash / Esmeralda Gomes / Nelson Almeida / Carlos Carpetudo

523 Trabalhos de documentação de arte paleolítica realizados no âmbito do projeto PalæoCôa André Tomás Santos / António Fernando Barbosa / Luís Luís / Marcelo Silvestre / Thierry Aubry

537 Imagens fantasmagóricas, silhuetas elusivas: as figuras humanas na arte do Paleolítico Superior da região do Côa Mário Reis

$55^{1}$ Os motivos zoomórficos representados nas placas de tear de Vila Nova de São Pedro (Azambuja, Portugal) Andrea Martins / César Neves / José M. Arnaud / Mariana Diniz

571 Arte Rupestre do Monte de Góios (Lanhelas, Caminha). Síntese dos resultados dos trabalhos efectuados em 2007-2009 Mário Varela Gomes

599 Gravuras rupestres de barquiformes no Monte de S. Romão, Guimarães, Noroeste de Portugal Daniela Cardoso

613 Círculos segmentados gravados na Bacia do Rio Lima (Noroeste de Portugal): contributos para o seu estudo Diogo Marinho / Ana M.S. Bettencourt / Hugo Aluai Sampaio

631 Equídeos gravados no curso inferior do Rio Mouro, Monção (NW Portugal). Análise preliminar Coutinho, L.M. / Bettencourt, A.M.S / Sampaio, Hugo A.S

645 Paletas na Arte Rupestre do Noroeste de Portugal. Inventário preliminar Bruna Sousa Afonso / Ana M. S. Bettencourt / Hugo A. Sampaio 


\section{Pré-História}

661 O projeto Miño/Minho: balanço de quatro anos de trabalhos arqueológicos Sérgio Monteiro-Rodrigues / João Pedro Cunha-Ribeiro / Eduardo Méndez-Quintas / Carlos Ferreira / Pedro Xavier / José Meireles / Alberto Gomes / Manuel Santonja / Alfredo Pérez-González

677 A ocupação paleolítica da margem esquerda do Baixo Minho: a indústria lítica do sítio de Pedreiras 2 (Monção, Portugal) e a sua integração no contexto regional Carlos Ferreira / João Pedro Cunha-Ribeiro / Sérgio Monteiro-Rodrigues / Eduardo Méndez-Quintas / Pedro Xavier / José Meireles / Alberto Gomes / Manuel Santonja / Alfredo Pérez-González

693 O sítio acheulense do Plistocénico médio da Gruta da Aroeira Joan Daura / Montserrat Sanz / Filipa Rodrigues / Pedro Souto / João Zilhão

703 As sociedades neandertais no Barlavento algarvio: modelos preditivos com recurso aos SIG

Daniela Maio

715 A utilização de quartzo durante o Paleolítico Superior no território dos vales dos rios Vouga e Côa

Cristina Gameiro / Thierry Aubry / Bárbara Costa / Sérgio Gomes / Luís Luís / Carmen Manzano / André Tomás Santos

733 Uma perspetiva diacrónica da ocupação do concheiro do Cabeço da Amoreira (Muge, Portugal) a partir da tecnologia lítica Joana Belmiro / João Cascalheira / Célia Gonçalves

745 Novos dados sobre a Pré-história Antiga no concelho de Palmela. A intervenção arqueológica no sítio do Poceirão I

Michelle Teixeira Santos

757 Problemas em torno de Datas Absolutas Pré-Históricas no Norte do Alentejo Jorge de Oliveira

771 Povoamento pré-histórico nas áreas montanhosas do NO de Portugal: o Abrigo 1 de Vale de Cerdeira Pedro Xavier / José Meireles / Carlos Alves

783 Apreciação do povoamento do Neolítico Inicial na Baixa Bacia do Douro. A Lavra I (Serra da Aboboreira) como caso de estudo Maria de Jesus Sanches

797 O Processo de Neolitização na Plataforma do Mondego: os dados do Sector C do Outeiro dos Castelos de Beijós (Carregal do Sal)

João Carlos de Senna-Martinez / José Manuel Quintã Ventura / Andreia Carvalho / Cíntia Maurício

823 Novos trabalhos na Lapa da Bugalheira (Almonda, Torres Novas) Filipa Rodrigues / Pedro Souto / Artur Ferreira / Alexandre Varanda / Luís Gomes / Helena Gomes / João Zilhão

837 A pedra polida e afeiçoada do sítio do Neolítico médio da Moita do Ourives (Benavente, Portugal)

César Neves

857 Casal do Outeiro (Encarnação, Mafra): novos contributos para o conhecimento do povoamento do Neolítico final na Península de Lisboa.

Cátia Delicado / Carlos Maneira e Costa / Marta Miranda / Ana Catarina Sousa

873 Stresse infantil, morbilidade e mortalidade no sítio arqueológico do Neolítico Final/ Calcolítico ( $4^{\circ}$ e $3^{\circ}$ milénio a.C.) do Monte do Carrascal 2 (Ferreira do Alentejo, Beja) Liliana Matias de Carvalho / Sofia N. Wasterlain 
885 Come together: O Conjunto Megalítico das Motas (Monção, Viana do Castelo) e as expressões Campaniformes do Alto Minho Ana Catarina Basílio / Rui Ramos

899 Trabalhos arqueológicos no sítio Calcolítico da Pedreira do Poio Carla Magalhães / João Muralha / Mário Reis / António Batarda Fernandes

913 O sítio arqueológico de Castanheiro do Vento. Da arquitectura do sítio à arquitectura de um território João Muralha Cardoso

925 Estudo zooarqueológico das faunas do Calcolítico final de Vila Nova de São Pedro (Azambuja, Portugal): Campanhas de 2017 e 2018 Cleia Detry / Ana Catarina Francisco / Mariana Diniz / Andrea Martins / César Neves / José Morais Arnaud

943 As faunas depositadas no Museu Arqueológico do Carmo provenientes de Vila Nova de São Pedro (Azambuja): as campanhas de 1937 a 1967 Ana Catarina Francisco / Cleia Detry / César Neves / Andrea Martins / Mariana Diniz / José Morais Arnaud

959 Análise funcional de material lítico em sílex do castro de Vila Nova de S. Pedro (Azambuja, Portugal): uma primeira abordagem Rafael Lima

971 O recinto da Folha do Ouro 1 (Serpa) no contexto dos recintos de fossos calcolíticos alentejanos

António Carlos Valera / Tiago do Pereiro / Pedro Valério / António M. Monge Soares

\section{Proto-História}

987 Produção de sal marinho na Idade do Bronze do noroeste Português. Alguns dados para uma reflexão

Ana M. S. Bettencourt / Sara Luz / Nuno Oliveira / Pedro P. Simões / Maria Isabel C. Alves / Emílio Abad-Vidal

1001 A estátua-menir do Pedrão ou de São Bartolomeu do Mar (Esposende, noroeste de Portugal) no contexto arqueológico da fachada costeira de entre os rios Neiva e Cávado Ana M. S. Bettencourt / Manuel Santos-Estévez / Pedro Pimenta Simões / Luís Gonçalves

1015 O Castro do Muro (Vandoma/Baltar, Paredes) - notas para uma biografia de ocupação da Idade do Bronze à Idade Média

Maria Antónia D. Silva / Ana M. S. Bettencourt / António Manuel S. P. Silva / Natália Félix

1031 Do Bronze Final à Idade Média - continuidades e hiatos na ocupação de Povoados em Oliveira de Azeméis João Tiago Tavares / Adriaan de Man

1041 As faunas do final da Idade do Bronze no Sul de Portugal: leituras desde o Outeiro do Circo (Beja)

Nelson J. Almeida / Íris Dias / Cleia Detry / Eduardo Porfírio / Miguel Serra

1055 A Espada do Monte das Oliveiras (Serpa) - uma arma do Bronze Pleno do Sudoeste Rui M. G. Monge Soares / Pedro Valério / Mariana Nabais / António M. Monge Soares

1065 São Julião da Branca (Albergaria-a-Velha) - Investigação e valorização de um povoado do Bronze Final

António Manuel S. P. Silva / Paulo A. P. Lemos / Sara Almeida e Silva / Edite Martins de Sá

1083 Do castro de S. João ao Mosteiro de Santa Clara: notícia de uma intervenção arqueológica, em Vila do Conde Rui Pinheiro 
1095 O castro de Ovil (Espinho), um quarto de século de investigação - resultados e questões em aberto

Jorge Fernando Salvador / António Manuel S. P. Silva

1111 O Castro de Salreu (Estarreja), um povoado proto-histórico no litoral do Entre Douro e Vouga

Sara Almeida e Silva / António Manuel S. P. Silva / Paulo A. P. Lemos / Edite Martins de Sá

1127 Castro de Nossa Senhora das Necessidades (Sernancelhe): uma primeira análise artefactual Telma Susana O. Ribeiro

${ }_{1141}$ A cividade de Bagunte. O estado atual da investigação Pedro Brochado de Almeida

1153 Zoomorfos na cerâmica da Idade do Ferro no NW Peninsular: inventário, cronologias e significado Nuno Oliveira / Cristina Seoane

1163 Vasos gregos em Portugal: diferentes maneiras de contar a história do intercâmbio cultural na Idade do Ferro

Daniela Ferreira

1175 Os exotica da necrópole da Idade do Ferro do Olival do Senhor dos Mártires (Alcácer do Sal) no seu contexto regional

Francisco B. Gomes

\section{Antiguidade Clássica e Tardia}

1191 O uso de madeira como combustível no sítio da Quinta de Crestelos (Baixo Sabor): da Idade do Ferro à Romanização Filipe Vaz / João Tereso / Sérgio Simões Pereira / José Sastre / Javier Larrazabal Galarza / Susana Cosme / José António Pereira / Israel Espi

1207 Cultivos de Época Romana no Baixo Sabor: continuidade em tempos de mudança? João Pedro Tereso / Sérgio Simões Pereira / Filipe Santos / Luís Seabra / Filipe Vaz

1221 A casa romana na Hispânia: aplicação dos modelos itálicos nas províncias ibéricas Fernanda Magalhães / Diego Machado / Manuela Martins

1235 As pinturas murais romanas da Rua General Sousa Machado, n. ${ }^{5}$ 1, Chaves José Carvalho

1243 Trás do Castelo (Vale de Mir, Pegarinhos, Alijó) - Uma exploração agrícola romana do Douro

Tony Silvino / Pedro Pereira

1255 A sequência de ocupação no quadrante sudeste de Bracara Augusta: as transformações de uma unidade doméstica Lara Fernandes / Manuela Martins

1263 Os Mosaicos com decoração geométrica e geométrico-vegetalista dos sítios arqueológicos da área do Conuentus Bracaraugustanus. Novas abordagens quanto à conservação, restauro, decoração e datação Maria de Fátima Abraços / Licínia Wrench

1277 “Casa Romana” do Castro de São Domingos (Cristelos, Lousada): Escavação, Estudo e Musealização Paulo André de P. Lemos

1291 A arqueobotânica no Castro de Guifões (Matosinhos, Noroeste de Portugal): O primeiro estudo carpológico

Luís Seabra / Andreia Arezes / Catarina Magalhães / José Varela / João Pedro Tereso 
1305 Um Horreum Augustano na Foz do Douro (Monte do Castelo de Gaia, Vila Nova de Gaia) Rui Ramos

1311 Ponderais romanos na Lusitânia: padrões, formas, materiais e contextos de utilização Diego Barrios Rodríguez

1323 Um almofariz centro-itálico na foz do Mondego

Marco Penajoia

1335 Estruturas romanas de Carnide - Lisboa Luísa Batalha / Mário Monteiro / Guilherme Cardoso

1347 O contexto funerário do sector da "necrópole NO" da Rua das Portas de S. Antão (Lisboa): o espaço, os artefactos, os indivíduos e a sua interconectividade na interpretação do passado Sílvia Loja, José Carlos Quaresma, Nelson Cabaço, Marina Lourenço, Sílvia Casimiro, Rodrigo Banha da Silva, Francisca Alves-Cardoso

${ }_{1361}$ Povoamento em época Romana na Amadora - resultados de um projeto pluridisciplinar Gisela Encarnação / Vanessa Dias

1371 A Arquitectura Residencial em Mirobriga (Santiago do Cacém): contributo a partir de um estudo de caso Filipe Sousa / Catarina Felício

${ }_{1385}$ O fim do ciclo. Saneamento e gestão de resíduos nos edifícios termais de Mirobriga (Santiago do Cacém)

Catarina Felício / Filipe Sousa

1399 Balsa, Topografia e Urbanismo de uma Cidade Portuária Vítor Silva Dias / João Pedro Bernardes / Celso Candeias / Cristina Tété Garcia

1413 No Largo das Mouras Velhas em Faro (2017): novas evidências da necrópole norte de Ossonoba e da sua ocupação medieval Ricardo Costeira da Silva / Paulo Botelho / Fernando Santos / Liliana Nunes

1429 Instrumentos de pesca recuperados numa fábrica de salga em Ossonoba (Faro) Inês Rasteiro / Ricardo Costeira da Silva / Paulo Botelho

1439 A Necrópole Romana do Eirô, Duas Igrejas (Penafiel): intervenção arqueológica de 2016 Laura Sousa / Teresa Soeiro

1457 Ritual, descarte ou afetividade? A presença de Canis lupus familiaris na Necrópole Noroeste de Olisipo (Lisboa)

Beatriz Calapez Santos / Sofia Simões Pereira / Rodrigo Banha da Silva / Sílvia Casimiro / Cleia Detry / Francisca Alves Cardoso

1467 Dinâmicas económicas em Bracara na Antiguidade Tardia Diego Machado / Manuela Martins / Fernanda Magalhães / Natália Botica

1479 Cerâmicas e Vidros da Antiguidade Tardia do Edifício sob a Igreja do Bom Jesus (Vila Nova de Gaia) Joaquim Filipe Ramos

1493 Novos contributos para a topografia histórica de Mértola no período romano e na Antiguidade Tardia Virgílio Lopes

\section{8. Época Medieval}

1511 Cerâmicas islâmicas no Garb setentrional "português": algumas evidências e incógnitas Constança dos Santos / Helena Catarino / Susana Gómez / Maria José Gonçalves / Isabel Inácio / Gonçalo Lopes / Jacinta Bugalhão / Sandra Cavaco / Jaquelina Covaneiro / Isabel Cristina Fernandes / Ana Sofia Gomes 
1525 Contributo para o conhecimento da cosmética islâmica, em Silves, durante a Idade Média Rosa Varela Gomes

1537 Yábura e o seu território - uma análise histórico-arqueológica de Évora entre os séculos VIII-XII José Rui Santos

1547 A encosta sul do Castelo de Palmela - resultados preliminares da escavação arqueológica Luís Filipe Pereira / Michelle Teixeira Santos

1559 A igreja de São Lourenço (Mouraria, Lisboa): um conjunto de silos e de cerâmica medieval islâmica

Andreia Filipa Moreira Rodrigues

1571 O registo material de movimentações populacionais no Médio Tejo, durante os séculos XII-XIII. Dois casos de "sunken featured buildings", nos concelhos de Cartaxo e Torres Novas Marco Liberato / Helena Santos / Nuno Santos

1585 O nordeste transmontano nos alvores da Idade média. Notas para reflexão Ana Maria da Costa Oliveira

1601 Sepulturas escavadas na rocha do Norte de Portugal e do Vale do Douro: primeiros resultados do Projecto SER-NPVD

Mário Jorge Barroca / César Guedes / Andreia Arezes / Ana Maria Oliveira

1619 "Portucalem Castrum Novum" entre o Mediterrâneo e o Atlântico: o estudo dos materiais cerâmicos alto-medievais do arqueossítio da rua de D. Hugo, nํ. 5 (Porto) João Luís Veloso

1627 A Alta Idade Média na fronteira de Lafões: notas preliminares sobre a Arqueologia no Concelho de Vouzela

Manuel Luís Real / Catarina Tente

1641 Um conjunto cerâmico medieval fora de portas: um breve testemunho aveirense Susana Temudo

${ }_{1651}$ Os Lóios do Porto: uma perspetiva integrada no panorama funerário da Baixa Idade Média à Época Moderna em meios urbanos em Portugal

Ana Lema Seabra

1659 O Caminho Português Interior de Santiago como eixo viário na Idade Média Pedro Azevedo

1665 Morfologia Urbana: Um exercício em torno do Castelo de Ourém André Donas-Botto / Jaqueline Pereira

1677 Intervenção arqueológica na Rua Marquês de Pombal/Largo do Espírito Santo (Bucelas, Loures)

Florbela Estêvão / Nathalie Antunes-Ferreira / Dário Ramos Neves / Inês Lisboa

1691 O Cemitério Medieval do Poço do Borratém e a espacialidade funerária na cidade de Lisboa Inês Belém / Vanessa Filipe / Vasco Noronha Vieira / Sónia Ferro / Rodrigo Banha da Silva

1705 Um Espaço Funerário Conventual do séc. XV em Lisboa: o caso do Convento de São Domingos da Cidade Sérgio Pedroso / Sílvia Casimiro / Rodrigo Banha da Silva / Francisca Alves Cardoso

\section{9. Época Moderna e Contemporânea}

1721 Arqueologia Moderna em Portugal: algumas reflexões críticas em torno da quantificação de conjuntos cerâmicos e suas inferências históricas e antropológicas Rodrigo Banha da Silva / André Bargão / Sara da Cruz Ferreira

1733 Faianças de dois contextos entre os finais do século XVI e XVIII do Palácio dos Condes de Penafiel, Lisboa

Martim Lopes / Tomás Mesquita 
1747 Um perfil de consumo do século XVIII na foz do Tejo: O caso do Mercado da Ribeira, Lisboa Sara da Cruz Ferreira / Rodrigo Banha da Silva / André Bargão

1761 Os Cachimbos dos Séculos XVII e XVIII do Palácio Mesquitela e Convento dos Inglesinhos (Lisboa)

Inês Simão / Marina Pinto / João Pimenta / Sara da Cruz Ferreira / André Bargão / Rodrigo Banha da Silva

1775 "Tomar os fumos da erua que chamão em Portugal erua sancta». Estudo de Cachimbos provenientes da Rua do Terreiro do Trigo, Lisboa

Miguel Martins de Sousa / José Pedro Henriques / Vanessa Galiza Filipe

1787 Cachimbos de Barro Caulínitico da Sé da Cidade Velha (República de Cabo Verde)

Rodrigo Banha da Silva / João Pimenta / Clementino Amaro

1801 Algumas considerações sobre espólio não cerâmico recuperado no Largo de Jesus (Lisboa) Carlos Boavida

1815 Adereços de vidro, dos séculos XVI-XVIII, procedentes do antigo Convento de Santana de Lisboa (anéis, braceletes e contas)

Joana Gonçalves / Rosa Varela Gomes / Mário Varela Gomes

1837 Da ostentação, luxo e poder à simplicidade do uso quotidiano: arqueologia e simbologia de joias e adornos da Idade Moderna Portuguesa Jéssica Iglésias

1849 Os amuletos em Portugal - dos objetos às superstições: o coral vermelho Alexandra Vieira

1865 Cerâmicas de Vila Franca de Xira nos séculos XV e XVI Eva Pires

1879 «Não passa por teu o que me pertence». Marcas de individualização associadas a faianças do Convento de Nossa Senhora de Aracoeli, Alcácer do Sal Catarina Parreira / Íris Fragoso / Miguel Martins de Sousa

1891 Cerâmica de Leiria: alguns focos de produção

Jaqueline Pereira / André Donas-Botto

1901 Os Fornos na Rua da Biquinha, em Óbidos Hugo Silva / Filipe Oliveira

1909 A casa de Pêro Fernandes, contador dos contos de D. Manuel I: o sítio arqueológico da Silha do Alferes, Seixal (século XVI) Mariana Nunes Ferreira

1921 O Alto da Vigia (Sintra) e a vigilância e defesa da costa Alexandre Gonçalves / Sandra Santos

1937 O contexto da torre sineira da Igreja de Santa Maria de Loures Paulo Calaveira / Martim Lopes

1949 A Necrópole do Hospital Militar do Castelo de São Jorge e as práticas funerárias na Lisboa de Época Moderna Susana Henriques / Liliana Matias de Carvalho / Ana Amarante / Sofia N. Wasterlain

1963 SAND - Sarilhos Grandes Entre dois Mundos: o adro da Igreja e a Paleobiologia dos ossos humanos recuperados

Paula Alves Pereira / Roger Lee Jesus / Bruno M. Magalhães

1975 Expansão urbana da vila de Cascais no século XVII e XVIII: a intervenção arqueológica na Rua da Vitória no 15 a 17

Tiago Pereira / Vanessa Filipe

1987 Novos dados para o conhecimento do Urbanismo de Faro em época Moderna Ana Rosa 
1995 Um exemplo de Arqueologia Urbana em Alcoutim: o Antigo Edifício dos CTT Marco Fernandes / Marta Dias / Alexandra Gradim / Virgílio Lopes / Susana Gómez Martínez

2007 Palácio dos Ferrazes (Rua das Flores/Rua da Vitória, Porto): a cocheira de Domingos Oliveira Maia

Francisco Raimundo

2021 As muitas vidas de um edifício urbano: História, Arqueologia e Antropologia no antigo Recreatório Paroquial de Penafiel Helena Bernardo / Jorge Sampaio / Marta Borges

2035 O convento de Nossa Senhora da Esperança de Ponta Delgada: o contributo da arqueologia para o conhecimento de um monumento identitário João Gonçalves Araújo / N’Zinga Oliveira

2047 Arqueologia na ilha do Corvo... em busca da capela de Nossa Senhora do Rosário Tânia Manuel Casimiro / José Luís Neto / Luís Borges / Pedro Parreira

2059 Perdidos à vista da Costa. Trabalhos arqueológicos subaquáticos na Barra do Tejo Jorge Freire / José Bettencourt / Augusto Salgado

2071 Arqueologia marítima em Cabo Verde: enquadramento e primeiros resultados do projecto CONCHA

José Bettencourt / Adilson Dias / Carlos Lima / Christelle Chouzenoux / Cristóvão Fonseca / Dúnia Pereira / Gonçalo Lopes / Inês Coelho / Jaylson Monteiro / José Lima / Maria Eugénia Alves / Patrícia Carvalho / Tiago Silva

2085 Trabalhos arqueológicos na Cidade Velha (Ribeira Grande de Santiago, Cabo Verde): reflexões sobre um projecto de investigação e divulgação patrimonial André Teixeira / Jaylson Monteiro / Mariana Mateus / Nireide Tavares / Cristovão Fonseca / Gonçalo C. Lopes / Joana Bento Torres / Dúnia Pereira / André Bargão / Aurélie Mayer / Bruno Zélie / Carlos Lima / Christelle Chouzenoux / Inês Henriques / Inês Pinto Coelho / José Lima / Patrícia Carvalho / Tiago Silva

2103 A antiga fortificação de Quelba / Khor Kalba (E.A.U.). Resultados de quatro campanhas de escavações, problemáticas e perspectivas futuras Rui Carita / Rosa Varela Gomes / Mário Varela Gomes / Kamyar Kamyad

2123 Colónias para homens novos: arqueologia da colonização agrária fascista no noroeste ibérico Xurxo Ayán Vila / José Mạ . Señorán Martín 


\title{
OS CACHIMBOS DOS SÉCULOS XVII E XVIII DO PALÁCIO MESQUITELA E CONVENTO DOS INGLESINHOS (LISBOA)
}

Inês Simão ${ }^{1}$, Marina Pinto ${ }^{1}$, João Pimenta ${ }^{2}$, Sara da Cruz Ferreira ${ }^{3}$, André Bargão ${ }^{4}$, Rodrigo Banha da Silva ${ }^{5}$

\begin{abstract}
RESUMO
Em 2004 e 2009 foram realizadas pela empresa Era-Arqueologia duas intervenções arqueológicas de carácter preventivo, decorrentes de projectos de reabilitação e reconversão de espaços na zona do Bairro Alto, em Lisboa. Sendo ambos os lugares de cronologia seiscentista, equivalem a bem distintos perfis socio-económicos de ocupação: o primeiro, o Venerável Colégio Pontifício de São Pedro e de São Paulo (vulgo Convento dos Inglesinhos), dedicado ao ensino católico da comunidade Inglesa; o segundo, o espaço residencial dos Condes de Mesquitela.

A despeito de todas as limitações contextuais arqueológicas, o estudo assinala as diferentes proporções com que os dois conjuntos se apresentam, deste modo se comprovando o uso dos cachimbos como indicador arqueológico significante para a análise dos espaços urbanos.

Palavras-chave: Cachimbos cerâmicos, Arqueologia Moderna, Arqueologia Conventual, Importações Cerâmicas, "Cultura do tabagismo".
\end{abstract}

\begin{abstract}
Era-Arqueologia excavated in 2004 and 2009 two significant buildings in Bairro Alto quarter in Lisbon, due to urban rehabilitation projects. With approximate $17^{\text {th }}$ century chronologies, they display very distinctive socioeconomic profiles: one, St. Peter's and St. Paul's Honourable Pontifical College (commonly known as the "Little English Convent"), and was devoted to catholic teaching to the British community living in Lisbon during Early Modern Age; the other, a noble mansion belonging to Mesquitela Earls.

Despite archaeological limitations of contextual data, they display some contrast between the religious context and the noble one, allowing some archaeological inference on social significance of pipe presence in Early Modern Age contexts from Lisbon.

Keywords: Clay Tobacco Pipes, Early Modern Archaeology, Conventual Archaeology, Pottery Consumption, "Tobacco Culture".
\end{abstract}

\section{INTRODUÇÃO}

Os cachimbos em cerâmica constituem, hoje, um domínio específico de estudo no âmbito das arqueologias moderna e colonial. Artefacto singular, de uso personalizado, detentor de uma funcionalidade úni- ca ao não poder ser reutilizado com outras finalidades, não só equivale a um útil "elemento-datante" como é de igual modo significante para outros níveis de inferência, ao documentar aspectos múltiplos da "cultura material": permite o estudo do hábito de consumo por inalação do tabaco, mas eventual-

\footnotetext{
1.Era-Arqueologia.inessimao@era-arqueologia.pt.marinapinto@era-arqueologia.pt

2. Uniarq-Centro de Arqueologia da Universidade de Lisboa. CEAX - Centro de Estudos Arqueológicos de Vila Franca de Xira; Joao-marques@cm-vxira.pt

3. Bolseira de Doutoramento FCT SFRH/BD/137142/2018. CHAM - NOVA FCSH; sara.isabel91@hotmail.com

4. Bolseiro de Doutoramento FCT SFRH/BD/133757/2017. CHAM - NOVA FCSH; andrebargao@gmail.com

5. CAL/DPC/CML. Departamento de História da FCSH. CHAM - NOVA FCSH; rodrigo.banha@cm-lisboa.pt
} 
mente também de outras substâncias psico-activas (Sousa, 2020), mas também disponibiliza evidências de conexões comerciais e, se bem manuseado, contribui para a definição de perfis sociais e culturais documentados pelos contextos arqueológicos.

\section{BREVE SINOPSE DOS ESTUDOS SOBRE CACHIMBOS EM LISBOA}

Para o caso da cidade de Lisboa, os primeiros elementos de cachimbo publicados equivalem aos colectados em 196o no remanescente do Hospital Real de Todos-Os-Santos, dependências do Convento de São Domingos e Colector Real de São Domingos por Irisalva Moita (1965, p. 75, Est. XV n.․ 212; três dos quatro que compunham o conjunto seriam mais tarde revisitados por Miguel Pombinho - Martins, 1988 - e expostos e de novo publicados no catálogo da exposição dedicada ao maior edifício da Lisboa Manuelina que teve lugar em 1993, de permeio com um bico de chaleira confundido com um cachimboPereira, 1993).

Fernando Rodrigues Ferreira daria a conhecer depois, em 1983, um outro fragmento de cachimbo procedente das suas escavações decorridas no Mosteiro de São Vicente de Fora, em Lisboa, ostentando marca britânica de John Stephens (Ferreira, 1983, p. 28).

Após um hiato, que se relaciona também com o historial do desenvolvimento das escavações na cidade (Caessa, Marques \& Silva, 2016), o estudo do conjunto amplo do Caminho da Ronda 1, no Castelo de São Jorge, apresentado em 2000 nas $4^{\text {a }}$ s Jornadas de Cerâmica Medieval e Pós-Medieval (Pimenta, Calado \& Silva, 2003; 2008), marcaria o ponto de viragem a partir do qual se encetou com um ritmo digno de nota a compulsão de conjuntos recolhidos em contextos variados na cidade de Lisboa. O século XXI marca, portanto, o início da compulsão deste tipo de elemento artefactual para Lisboa, reconhecendo-se-lhe a alta valia informativa de há muito assinalada para a leitura da cidade (Silva \& Guinote, 1998).

De entre os estudos entretanto publicados no século actual, são vários os que merecem nota de destaque. Em primeiro lugar, e em função dos seus números elevados, os expressivos conjuntos recolhidos no Mercado da Ribeira (Pinto, Filipe \& Miguel, 2011) e Palácio dos Marqueses de Marialva (Calado et al., 2013). Em segundo lugar, e por um critério de alta valia metodológica, dado o tratamento quantitativo da representatividade dos cachimbos no universo da amostragem geral e em função da sequência estratigráfica, os estudos de Sara Ferreira (2015), a propósito do Forte de São Paulo, e de Filipe Santos Oliveira (2012), a propósito de um contexto doméstico urbano no Beco das Barrelas, em Alfama.

Pelo seu exotismo, já antes sugerido através do achado de um exemplar oriental colectado no Caminho da Ronda 1 (Pimenta, Guinote \& Silva, 2008), merece de igual modo saliência, pelo seu potencial significado, o conjunto coerente e bastante dissonante de todo o restante quadro até então conhecido para a cidade dado a conhecer pelo trabalho académico de Miguel Martins de Sousa, que tratou os cachimbos colectados na escavação do Terreiro do Trigo (Sousa, 2020).

Por fim, o esclarecimento, produzido de forma categórica, da existência de uma produção de cachimbos cerâmicos em pasta vermelha na capital, antes defendida com base num sítio de consumo (Pimenta, Calado \& Silva, 2008), viu-se confirmada pela publicação de Filipe Santos Oliveira dos restos de produção em contexto estratigráfico das antigas olarias do Monte de São Gens exumados, na actual Rua Damasceno Monteiro (Oliveira, 2019).

\section{ENQUADRAMENTO HISTÓRICO}

Os dois espaços aqui em análise enquadram-se no "Bairro Alto», segmento do tecido urbano lisboeta de características singulares em termos históricos e de morfologia urbana. De facto, a origem deste sector da cidade correlaciona-se directamente com o aumento da pressão resultante do acelerado crescimento demográfico verificado ao longo da segunda metade do séc. $\mathrm{XV}$, resultando da expansão para poente dos antigos limites medievos da cidade corporizados pela muralha fernandina (1373-1375), dada a progressiva exaustão dos espaços agrários intra-muros, ocupados por mais densa edificação ao longo de quatrocentos (Figura 1).

Deste modo, os terrenos irão ser parcelados em talhões e sub-aforados por Bartolomeu de Andrade e Francisca Cordovil para a construção de novas casas e hortas a partir de 1513, de onde deriva o primitivo nome do "Bairro Alto", "Vila Nova de Andrade» (Carita, 1994, pp. 19-21; Pinto, 2004, p. 10), estendendo-se desde as portas de Santa Catarina até à Igreja das Chagas (Carita, 1994, p. 25), com um desenho regular e evocador de uma nova concepção do espaço urbano de cariz renascentista. 
Seria em pleno «Bairro Alto» que se instalaria o Convento dos Inglesinhos. A sua construção enquadra-se no clima de intolerância religiosa que tem lugar na Europa quinhentista e seiscentista, no caso particular inglês das fortes perseguições aos católicos movidas pelo anglicanismo durante os reinados de Isabel I e Jaime I, que aliás dão origem à fixação de comunidades oriundas das Ilhas Britânicas em Lisboa (Figura 2).

Seria o convento flamengo de Douai, fundação outorgada por Filipe I de Portugal com a finalidade de acolher jovens dissidentes ingleses que pretendessem receber uma formação católica, a servir de exemplo para a fundação ulterior de outras casas e conventos na Europa, casos de Roma (1579), Valladolid (1589), Sevilha (1592) e Lisboa (AA.VV., 2007, p. 25; Lima, 1950, p. 105; Pinto, 2004, p. 11). No caso da capital portuguesa, seria a capacidade de iniciativa do reitor da Residência Inglesa ali sediada, o Padre Newman, que perseguiria a intenção do seu antecessor em fundar um seminário inglês em Lisboa, para o que conseguiu o apoio e suporte financeiro do nobre português D. Pedro Coutinho e obteve a autorização das autoridades eclesiásticas em Inglaterra e a permissão do monarca português Filipe III em Madrid, em 1621 (AA.VV., 2007, p. 26; Lopes, 1950, p. 106).

Com o parecer favorável do Reino e de Roma, é emitida em 20 de Novembro de 1621 a carta régia relativa à fundação do seminário e, em 1622, a bula papal de Gregório XV concedia ao Colégio todos os privilégios de que usufruíam outras instituições do mesmo género (Carita, 1994: 96; AAVV, 2007: 31). O Colégio recebe o nome de São Pedro, ao qual foi dedicada a construção da igreja nele existente, e de São Paulo, ficando a ser conhecido popularmente por "Convento dos Inglesinhos", nome dado pelos habitantes do "Bairro Alto", ou por "Lisbon College», para os que o frequentavam. O nome popular, dado pelos habitantes locais, pode dever-se à clausura que a formação impunha aos alunos (Lopes, 1950, p. 105; AA.VV., 2007, p. 31).

Os trabalhos de edificação iniciaram-se a 1632, tendo ficado concluído em 1644, e o seu espaço era considerado limitado, uma vez que a construção reaproveitou a existência de anteriores e antigas habitações (Carita, 1994, p. 96).

A mole construída sofreria danos assinaláveis com o cataclismo de 1755, devendo aqui referir-se o falecimento do capelão Dr. Manley sob os escombros do colapso da torre do templo, o que aliás consta do epitáfio funerário da sua lápide sepulcral patente no templo. Tendo os ocupantes abandonado o espaço temporariamente, seria ocupado como refúgio de famílias desalojadas, e certas áreas, como o corredor, usadas com funções hospitalares. Após o retorno ao espaço, a instituição sofreria de novo com a ocupação pelas tropas francesas, não tendo porém cessado o ensino, que teria continuidade até 1882, muito para além do estabelecimento da liberdade religiosa no Reino Unido, ocorrida em 1829 (Pinto, 1993, p. 4). Entre 2004 e 2009, o complexo edificado seria adquirido para a instalação de um condomínio de luxo (Figura 3).

O Palácio Mesquitela resulta da reconversão urbana do espaço que por via do seu primeiro casamento o Doutor António de Sousa de Macedo promove. Figura destacada dos reinados de D.João IV e D.Afonso VI, jurista, escritor, diplomata e político, seria agraciado por ambos os monarcas com diversas mercês e correspondentes proventos para si e para seu filho único, Luis Gonçalo de Sousa de Macedo. O seu trajecto conduzi-lo-ia às funções de Secretário de Estado de D. Afonso VI. O mais significativo de todos foi certamente o título de Barão da Ilha Grande de Joanes para este, que lhe permitiu entrar no primeiro grau da nobreza titulada, embora sem grandeza.

Merece também referência, pela singularidade peculiar, mas muito significativa, a outorga do título de Barão de Mulingar com que o Rei Carlos II de Inglaterra reconheceu os serviços prestados em condições especialmente adversas a seu pai o Rei Carlos I, que à semelhança do título português de Barão recaiu directamente em D. Luis Gonçalo (Pinto \& Simão, 2009, p. 14). Desenvolveria este último uma política de casamentos com elementos da mais alta nobreza, o primeiro com os Menezes, de muito curta duração, e o segundo com D. Mariana de Távora, promissor não apenas pelos oito filhos que lhe deu, mas também por ter sido esta senhora a herdeira da Casa de sua mãe, permitindo acrescentar dois morgados com inúmeras propriedades no Alto Alentejo (Portalegre, Castelo de Vide, Marvão, Arronches, Veiros, Monforte), e por ter estabelecido uma aliança com os Furtado de Mendonça, família com inúmeras influências na Corte e na hierarquia religiosa, além de ter beneficiado com as mercês dos serviços que, como militar valoroso na Guerra da Restauração, recebeu o irmão D. João Furtado de Mendonça, que veio a morrer solteiro (Pinto \& Simão, 2009, p. 14). A documentação manuscrita, rica e diversificada, 
atesta os trabalhos sucessivos de configuração do espaço envolvendo profundas reformulações urbanas promovidas por D. António e D. Luís Gustavo ao longo da segunda metade do séc. XVII, prosseguidas na sequência das afectações provocadas por 1755 até à segunda metade do séc. XVIII pelo $1^{\circ}$ Visconde de Mesquitela, D. Luís de Sousa de Macedo, e que emprestaram ao complexo a feição modular que facilmente se lhe reconheceu (Pinto \& Simão, 2009, pp. 22-26, 79-102).

Como o conjunto urbano anterior dos Inglesinhos, também o Palácio Mesquitela foi alvo de um processo de renovação promovido por um investidor imobiliário, despoletando as intervenções arqueológicas, concluídas em 2009.

\section{OS CONJUNTOS DE CACHIMBOS CERÂMICOS}

\subsection{O conjunto do "Convento dos Inglesinhos"}

O conjunto colectado nas intervenções arqueológicas realizadas no local é composto por um total de 35 framentos (MNI), dos quais 5 equivalem a porções preservando o fornilho ou vestígios deste, e os restantes a hastes.

O conjunto revelou uma distribuição regular e homogénea dos exemplares, não se verificando a sua concentração em qualquer das zonas específicas sondadas. Nota-se, aliás, uma dispersão pelas estratigrafias representativas das várias acções construtivas dos séculos XVII ao XIX, ilustrando algumas destas ocorrências,pelas cronologias relativas dos exemplares, fenómenos de remobilização dos materiais, "empacotados" em formações deposicionais de cronologias ulteriores, à semelhança de outras categorias cerâmicas coevas dos mesmos com eles reveladas.

São assaz interessantes no interior do conjunto alguns exemplares de fornilhos como os C.Ing. 13, C.Ing. 14 e C.Ing. 22, equivalentes tipologicamente a produções quase de certeza britânicas enquadradas em cronologias centradas no segmento temporal de 1640-1670, de acordo com as propostas de evolução morfológica de Akinson e Oswald (1969), com o primeiro dos citados a poder equivaler a um exemplar de mais recuada datação.

Em contraponto com estes, C.Ing. 15 e C.Ing. 16, parecem equivaler a produções holandesas de Gouda. A sua forma, segundo Duco, aponta já para o século XVIII pleno e enquadrado no lapso entre 1725 e 1750
(Duco, 2003), que a ausência de marcas infelizmente não permite precisar quanto ao produtor. $\mathrm{A}$ excepção é a marca lateral, parcial, do exemplar C.Ing. 16, por nós interpretada como "Rosa Tudor". Trata-se de uma versão impressa de forma deficiente e, sobretudo, muito simplificada em relação ao motivo original, que os produtores holandeses tomaram dos fabricos britânicos no séc. XVII, período durante o qual conhece franca vitalidade, muitas vezes com letras identificativas ou coroado, e que acabará por sobreviver de forma limitada já dentro do séc. XVIII (Bradley \& DeAngelo, 1981) (Figura 4).

\subsection{O conjunto do Palácio Mesquitela.}

No Palácio dos Condes de Mesquitela se recolheram 17 fragmentos de cachimbo em cerâmica, dos quais 3 preservando o fornilho, equivalendo os restantes a porções de haste.

O exemplar P.Mes.13 é um interessante fornilho de produção inglesa do século XVII. Segundo proposta tipológica da evolução dos fornilhos já antes citada de Atkinson e Oswald (1969), deverá datado de 1600-1640, data anterior à vida do Palácio e deveras interessante para Lisboa, ao documentar o consumo de tabaco por inalação num momento na zona do Bairro Alto, constituindo um dos cachimbos de potencial mais recuada data na cidade no estado actual dos nossos conhecimentos. Ostenta a marca $\mathrm{RB}$, encontrando-se o $\mathrm{B}$ mal gravado, como é normal nesta "assinatura", correspondente ao produtor Richard Berryman, activo na cidade de Bristol no período 1619-1652, (Jackson \& Price, 1974; Walker, 1971), detendo a impressão um excelente paralelo no País Basco, em Gipuzkoa (López Colom, 1999, p. 120).

Os outros dois fragmentos preservando o fornilho, P.Mes.15 e P.Mes.17, são como elaborações lisboetas seiscentistas facilmente rastreáveis pela sua pasta vermelha e pela morfologia. Como referimos em apartado anterior, este fabrico encontra-se para já documentado categoricamente nos despejos de olaria da encosta da Graça por Filipe Oliveira (2019), sendo que a esta produção se pode também assimilar o exemplar de haste P.Mes.16.

P.Mes.02, 03 e 11 mostram decoração impressa incisa na parte mesial da haste, sendo que qualquer um deles equivale produções holandesas de Gouda com cronologias situadas entre os finais do séc. XVII e os meados do séc. XVIII (Duco, 2003) (Figura 5). 


\section{DISCUSSÃO}

Os dois conjuntos objecto de análise revelam números globalmente baixos e na aparência não muito díspares, ilustrando o consumo de tabaco por inalação em contextos distintos da sociedade moderna da zona do Bairro Alto, em Lisboa, ao longo de uma cronologia longa, que cobre desde os finais do primeiro quartel do séc. XVII aos meados do séc. XVIII. As evidências lisboetas já conhecidas vêm comprovando que os cachimbos detêm um valor instrumental na definição dos perfis de composição dos contextos da cidade, onde as elevadas quantidades registadas, casos dos c.90o exemplares do Caminho da Ronda 1 (Castelo de São Jorge - Pimenta et al. 2008) e dos c.8oo do Mercado da Ribeira (espaço confinante com o antigo Forte de São Paulo (Pinto, Filipe \& Miguel, 2011), espaços bem diversificados mas que partilham em comum a sua associação a ambientes militares setecentistas, são fortemente constrastantes com outros pontos arqueológicos da cidade para os quais o conhecimento histórico por via documental demonstra outro tipo de perfil socio-económico, que a escassez de cachimbos parece comprovar: cite-se, a esse propósito, o exaustivo estudo contextual e estratigráfico desenvolvido sobre o ambiente doméstico do Beco das Barrelas, em Alfama, nomeadamente a ausência de cachimbos no "momento I" ( $2^{\underline{a}}$ met. séc. XVI - $1^{\circ}$ terço do séc. XVII), o surgimento de 6 exemplares no "momento II" (meados séc. XVII) e de 9 no "momento III" (finais do séc. XVII - inícios do séc. XVIII), quando em todos os momentos os artefactos de outras naturezas são ali relativamente abundantes (Oliveira, 2012, pp. 71-72).

Como é compreensível, os dados terão de ser colocados em comparação com outros similares da cidade, cuja publicação todavia escasseia apesar do elevado número de intervenções arqueológicas em Lisboa. Podem-se esgrimir desde já dados quantitativos, ainda que forçosamente conseguidos mediante uma elaboração grosseira nossa em termos metodológicos, porque não leva em conta factores importantes como o perfil funcional de formação desses mesmos contextos, por realizar na totalidade dos casos: deste modo, no Palácio dos Marqueses de Marialva (aproveitando-se aqui para relembrar os habitantes do espaço até à data do grande terramoto de Lisboa, o $2^{\circ}$ e $04 . .^{\circ}$ Marquês de Marialva, ligados a importantes funções militares na proximidade da coroa), se estudaram 703 fragmentos (Calado et al., 2013), numa área palaciana aproximada de $1500 \mathrm{~m}^{2}$, a que corresponderia um ratio de $0,47 / \mathrm{m}^{2}$; em Mercado da Ribeira, nos c. $760 \mathrm{~m}^{2}$ se estudaram 935, construindo um ratio de $1,23 / \mathrm{m}^{2}$ (Pinto, Filipe \& Miguel, 2011); em Beco das Barrelas (antes citados), em c. de $240 \mathrm{~m}^{2}$ equivalentes a duas habitações do bairro de Alfama, se identificaram somente 15, resultando num ratio de $0,04 / \mathrm{m}^{2}$ (Oliveira, 2012); por fim, em Caminho da Ronda 1 se consideraram 817 fragmentos, oriundos de um espaço de $150 \mathrm{~m}^{2}$, resultando num ratio de $5,45 / \mathrm{m}^{2}$ (Pimenta, Calado \& Silva, 2008).

Mesmo que declaradamente imprecisos (e impressionistas!), os valores deste modo obtidos ajudam metodologicamente a colocar em perspectiva os resultados obtidos para os dois locais objecto do presente estudo. Deste modo, é assinalável que para a área intervencionada do Palácio Mesquitela, onde se obtém um ratio de $0,05 / \mathrm{m}^{2}$, os indicadores são consentâneos com o outro disponível em Lisboa e associável a ambientes de carácter doméstico, mas declaradamente distante do ambiente palaciano dos Marqueses de Marialva, onde potencialmente o factor militar de uma parte dos seus frequentadores poderá ter jogado um papel de relevo. Em contraste com aqueles, os $0,45 / \mathrm{m}^{2}$ do antigo "Venerável Colégio Pontifício de São Pedro e de São Paulo", valores próximos dos obtidos no ambiente Marialva, geograficamente não muito distantes um do outro, terão que encerrar explicações de outro cariz, podendo desde já aventar-se que os números estarão eventualmente a espelhar um outro tipo de perfil social e, sobretudo, cultural, considerando aqui a enraizada tradição britânica de consumo do tabaco mediante cachimbo, hábito que terá tido neste espaço de ensino um ambiente deveras propício.

\section{BIBLIOGRAFIA}

AA. VV. (2007) - Convento dos Inglesinhos / The English College. Lisboa: Highgrove - Clubes residenciais, S.A.

ATKINSON, David R.; OSWALD, Adrian (1969) - London clay tobacco pipes. In Journal of the British Archaeological Association (3d Series), n. ${ }^{3}$ 2, fasc.1. Londres: British Archaeological Association, pp. 171-227.

BRADLEY, James; DEANGELO, Gordon (1981) - European clay pipe marks from $17^{\text {th }}$ century Onondaga Iroquois sites. In Archaeology of Eastern North America, 9. S.1.: Eastern States Archaeological Federation, pp. 109-133. 
CALADO, Marco; PIMENTA, João, SILVA, Rodrigo Banha da (2003) - Cachimbos de cerâmica provenientes da escavação do Caminho de Ronda no Castelo de São Jorge em Lisboa. In Património Estudos, 5. Lisboa: IPPAR, pp. 83-95.

CALADO, Marco, PIMENTA, João, FERNANDES, Lídia; MARQUES, António (2013) - Os cachimbos cerâmicos do Palácio Marialva, in Revista Portuguesa de Arqueologia, vol. 16. Lisboa: IPPAR, pp. 383-392.

CARITA, Hélder (1994) - Bairro Alto - Tipologias e modos arquitectónicos. Lisboa: Câmara Municipal de Lisboa.

DAVEY, Peter (Ed.) (1978) - The Archaeology of the clay tobacco pipe III Britain: the north and west. Oxford: British Council for Arqchaeology (col. BAR, British Series: 78), pp. 40-272.

DUCO, Don H. (1982) - Merken van Goudse Pijpenmakers 1660-1940. Amsterdam: Pijpenkabinet.

DUCO, Don H. (2003) - Merken in merkenrecht van de pijpenmakers in Gouda. Amsterdam: Pijpenkabinet.

FERREIRA, Fernando E. Rodrigues (1983) - Escavações do ossário de S. Vicente de Fora, in Revista Municipal, Ano

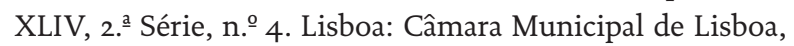
pp. 5-36.

FERREIRA, Sara (2015) - O sítio do Forte de São Paulo: estudo arqueológico da Ribeira Ocidental de Lisboa na Época Moderna. Lisboa: Faculdade de Ciências Sociais e Humanas da Universidade Nova de Lisboa (Dissertação de Mestrado).

JACKSON, Reginald Graham; PRICE, Roger Harvey (1974) - Bristol Clay Pipes a study of makers and their marks. In Research Monograph N.ำ 1. Bristol: City Museum, pp. 32-89.

LÓPEZ COLOM, Maria del M. (1999) - Pipas de Arcilla Halladas en Gipuzkoa. aproximación a su catalogación arqueológica y tipológica. Coleccion Hurbil. 1. Serie de monografias de arqueologia postmedieval. Gipuzkoa: Diputación Foral de Gipuzkoa.

MARTINS, Miguel (1988) - Três cachimbos do Hospital Real de Todos-Os-Santos, in Revista Municipal, Ano XLIX, 2..$^{\text {a }}$ Série, n. ํㅜㄹ. Lisboa: Câmara Municipal de Lisboa, pp. 16-18.

OLIVEIRA, Filipe (2012) - Espólio de Idade Moderna, proveniente do Beco das Barrelas, Alfama, Lisboa. Lisboa: Faculdade de Ciências Sociais e Humanas da Universidade Nova de Lisboa (Dissertação de Mestrado).

OLIVEIRA, Filipe Santos (2019) - Produção de cachimbos de barro na Rua Damasceno Monteiro (Olarias de São Gens), Lisboa - um contributo para o seu estudo, in Apontamentos de Arqueologia e Património, nº 13. Linda-a-Velha: Era-Arqueologia, pp. 67-73.
PIMENTA, João; CALADO, Marco; SILVA, Rodrigo Banha da (2008) - Cachimbos de cerâmica provenientes da escavação do Caminho da Ronda no Castelo de São Jorge, Lisboa , in ABRAÇOS, Hélder e DIOGO, João (Eds.) Actas das $4^{\underline{a}} s$ Jornadas de Cerâmica Medieval e Pós-Medieval (Tondela, 2000). Tondela: Câmara Municipal de Tondela, pp. 335-353.

PINTO, Marina Paiva (2004) - Relatório de Trabalhos Arqueológicos - Convento dos Inglesinhos, 2004. Lisboa: ERA, Arqueologia S.A.

PINTO, Marina; SIMÃO, Inês (2009) - Trabalhos Arqueológicos no Palácio da Mesquitela, Lisboa. Lisboa: Era-Arqueologia S.A.

PINTO, Marina; FILIPE, Iola; MIGUEL, Lúcia (2011) - Cachimbos de caulino provenientes do Mercado da Ribeira: contributo para a história socio-económica da Lisboa Moderna, in Apontamentos de Arqueologia e Património, $\mathrm{n}^{\circ} 7$. Linda-a-Velha: Era-Arqueologia, pp. 41-47.

SOUSA, Miguel Martins de (2020) - As evidências dos Estados Alterados de Consciência no registo arqueológico da Idade Moderna em Portugal. Lisboa: Faculdade de Ciências Sociais e Humanas da Universidade Nova de Lisboa (Dissertação de Mestrado).

WALKER, Ian C. (1971) - The Bristol Clay Tobacco-Pipe Industry. Bristol. City Museum. 


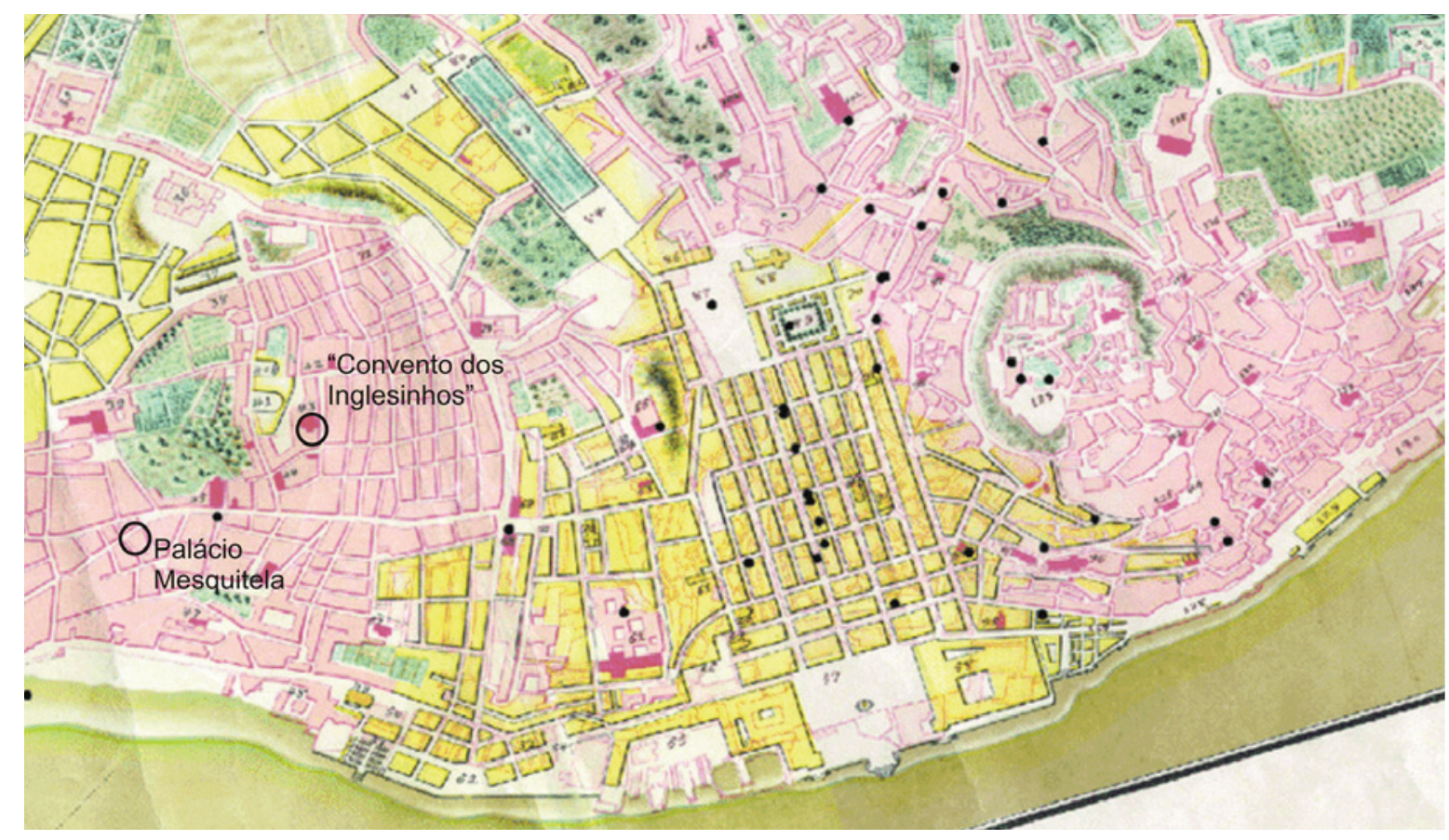

Figura 1 - Excerto da planta de Lisboa (anterior a 1780, Gabinete de Estudos Olisiponenses, CML), com localização do “Convento dos Inglesinhos” e do Palácio Mesquitela.

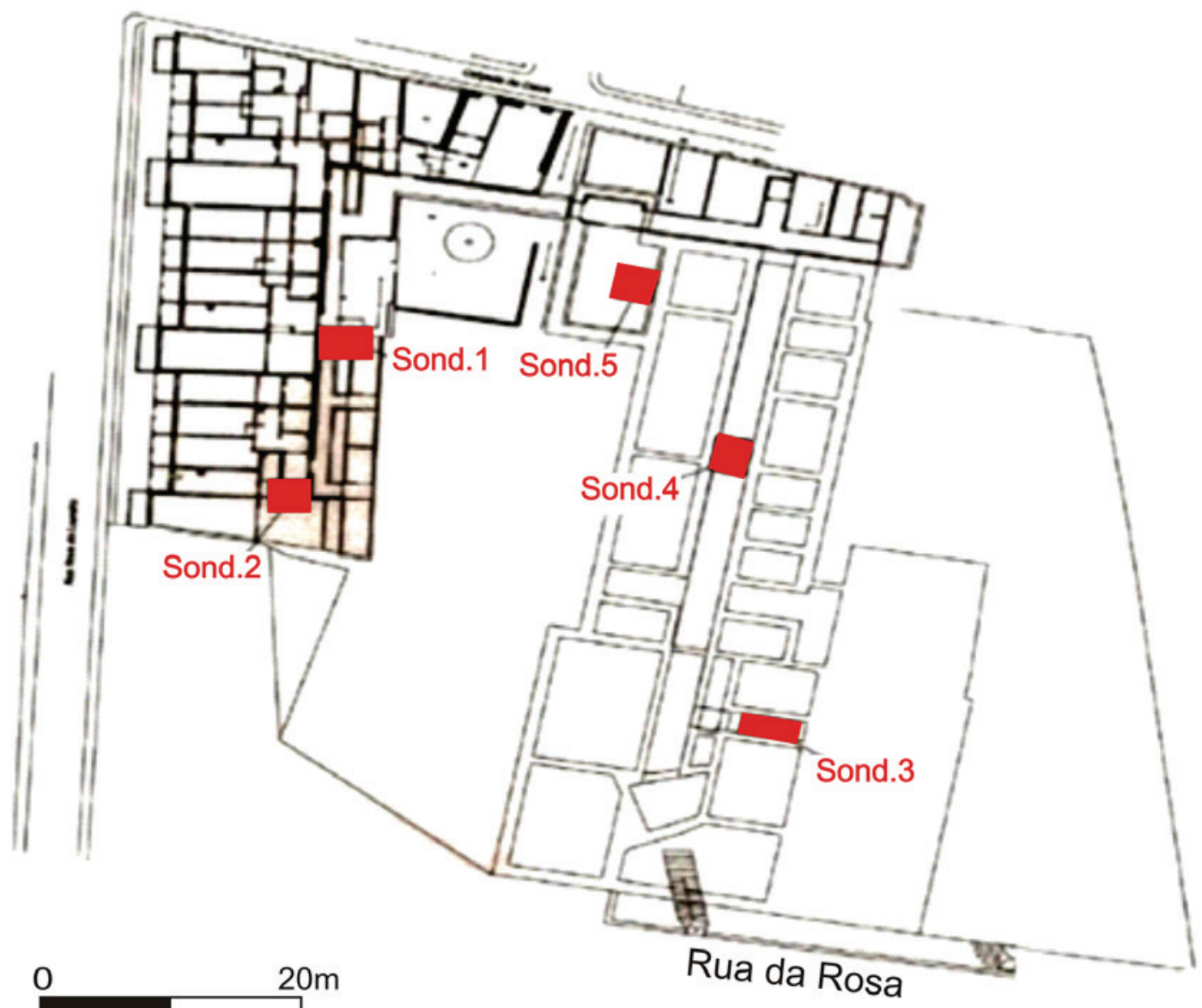

Figura 2 - Áreas intervencionadas pela I.A.U. do “Conventos dos Inglesinhos” (seg. Pinto, 2004). 


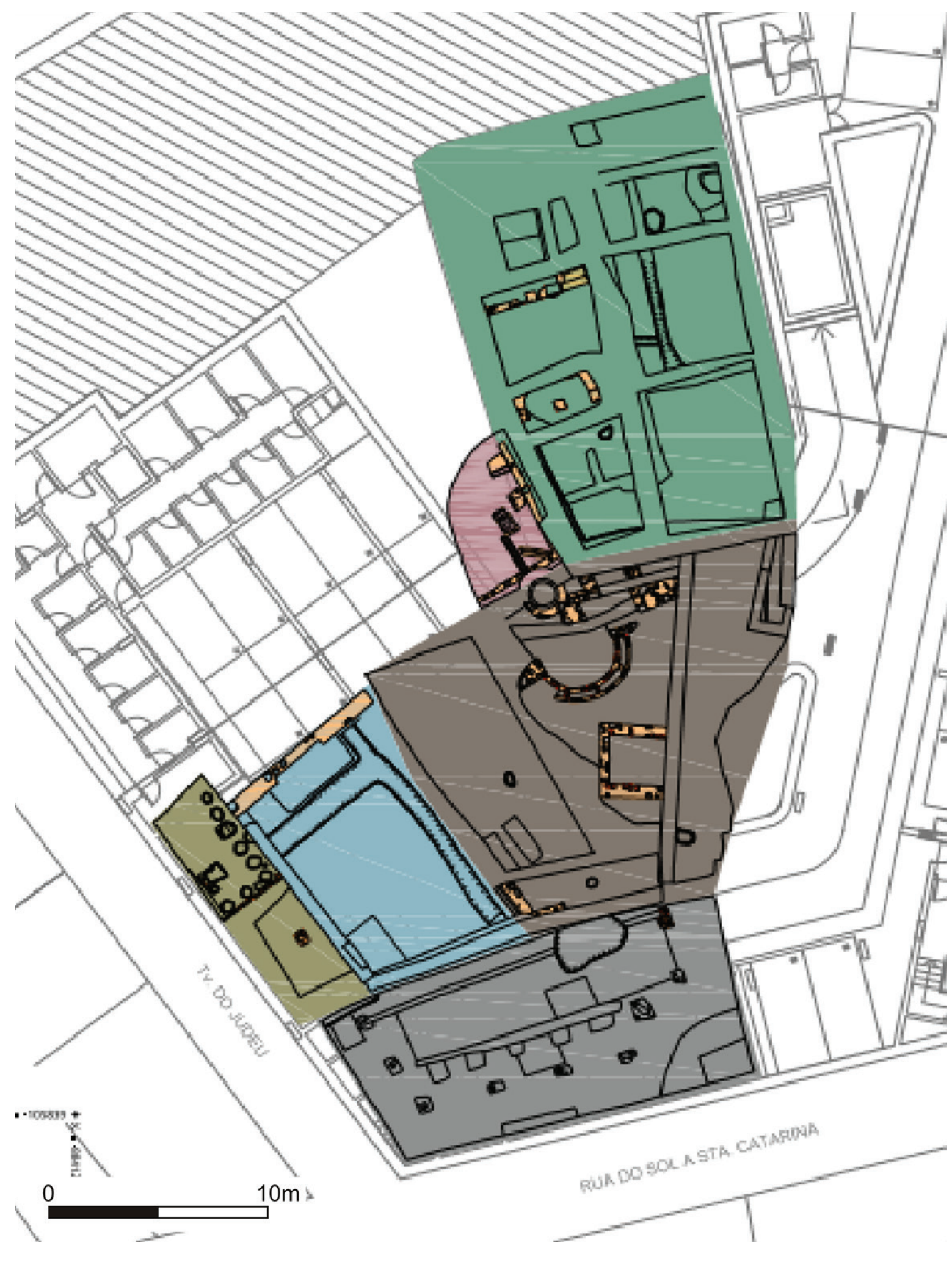

Figura 3 - Área intervencionada e estruturas reveladas pela I.A.U. do Palácio Mesquitela (seg. Pinto e Simão, 2009). 


\begin{tabular}{|c|c|c|c|c|c|c|c|c|c|c|c|c|c|c|c|c|c|c|c|c|c|c|c|}
\hline \multirow{4}{*}{ Inv. 2} & \multirow{2}{*}{\multicolumn{2}{|c|}{$\begin{array}{c}\text { Ind. } \\
\text { Contextuais }\end{array}$}} & \multirow{2}{*}{\multicolumn{6}{|c|}{ Porção }} & \multicolumn{8}{|c|}{ Caract. Fornilho } & \multicolumn{7}{|c|}{ Caract. Haste } \\
\hline & & & & & & & & & & & & & \multicolumn{4}{|c|}{ Decoração } & \multicolumn{5}{|c|}{ Dimensões } & \multicolumn{2}{|c|}{ Decoração } \\
\hline & \multirow[b]{2}{*}{ U.E. } & \multirow[b]{2}{*}{ Sond. } & \multirow[b]{2}{*}{ Forn. } & \multirow[b]{2}{*}{ Ped. } & \multicolumn{3}{|c|}{ Haste } & \multirow[b]{2}{*}{ Boq. } & \multicolumn{4}{|c|}{ Dimensões } & \multirow[b]{2}{*}{$\mathrm{sim}$} & \multirow[b]{2}{*}{ Não } & \multicolumn{2}{|c|}{ Marca de Produtor } & & Distal. & $\begin{array}{l}\text { Diâm. } \\
\text { Distal. }\end{array}$ & $\begin{array}{l}\text { Diâm. } \\
\text { Prox. }\end{array}$ & $\begin{array}{l}\text { Diâm. } \\
\text { Prox. }\end{array}$ & & \\
\hline & & & & & \begin{tabular}{|l|} 
Distal \\
\end{tabular} & Mesial & roxima & & iâm. $\mathrm{Fo}$ & ầm. $\mathrm{Ha}$ & m. Orif. & Penú & & & Sim & Não & Comp. & Ext. & & & & $\operatorname{sim}$ & Não \\
\hline C.Ing. 1 & [1020] & 1 & & & & & & $x$ & & & & & & & & & & & & & & & \\
\hline C.Ing. 2 & [1033] & 1 & & & & & $x$ & & & & & & & & & & 3,2 & 0,6 & 0,4 & 0,5 & 0,3 & & $x$ \\
\hline C. Ing. 3 & [1037] & 1 & & & & $x$ & & & & & & & & & & & 6,6 & 0,7 & 0,3 & 0,6 & 0,2 & & $x$ \\
\hline C.Ing. 4 & [2001] & 2 & & & & & $x$ & & & & & & & & & & 2,3 & 0,7 & 0,3 & 0,7 & 0,3 & & $x$ \\
\hline C.Ing. 5 & [2001] & 2 & & & $x$ & & & & & & & & & & & & 4,3 & 1 & 0,3 & 0,9 & 0,3 & & $x$ \\
\hline C.Ing. 6 & {$[2014]$} & 2 & & & $x$ & & & & & & & & & & & & 3,4 & 0,8 & 0,2 & 0,8 & 0,2 & & $x$ \\
\hline C.Ing. 7 & [2020] & 2 & & & & & $x$ & & & & & & & & & & 2,6 & 0,6 & 0,2 & 0,6 & 0,2 & & $x$ \\
\hline C.Ing. 8 & {$[2020]$} & 2 & & & & & $x$ & & & & & & & & & & 3,9 & 0,7 & 0,3 & 0,7 & 0,3 & & $\mathrm{x}$ \\
\hline C.Ing. 9 & [2029] & 2 & & & & & $x$ & & & & & & & & & & 4,4 & 0,7 & 0,3 & 0,6 & 0,3 & & $x$ \\
\hline C.Ing. 10 & [2029] & 2 & & $x$ & $x$ & & & & & & & 0,3 & & & & $x$ & 2,1 & 0,7 & 0,2 & 0,7 & 0,2 & & $x$ \\
\hline C.Ing. 11 & [3003] & 3 & & & $\mathrm{x}$ & & & & & & & & & & & & 4,5 & 0,8 & 0,3 & 0,7 & 0,3 & & $x$ \\
\hline C.Ing. 12 & [3003] & 3 & & & $\mathrm{x}$ & & & & & & & & & & & & 2,6 & 0,7 & 0,3 & 0,7 & 0,3 & & $x$ \\
\hline C.Ing. 13 & [3003] & 3 & $x$ & $x$ & $x$ & & & & 1,2 & 1,1 & 0,3 & 1,1 & B1 & & & $x$ & & & & & & & \\
\hline C.Ing. 14 & [3003] & 3 & $x$ & $x$ & $\mathrm{x}$ & & & & 1,2 & 0,9 & 0,3 & 1,4 & \begin{tabular}{|l|} 
B1 \\
\end{tabular} & & & $x$ & & & & & & & \\
\hline C. Ing. 15 & [4018] & 4 & & & & & $x$ & & & & & & & & & & 2,2 & 0,7 & 0,2 & 0,7 & 0,2 & & $x$ \\
\hline C. Ing. 16 & {$[4018]$} & 4 & $x$ & & & & & & 1,7 & 0,8 & 0,2 & 0,4 & B1 & & Rosa Tudor & & & & & & & & \\
\hline C. Ing. 17 & [4022] & 4 & & & & & $x$ & & & & & & & & & & 8,7 & 0,6 & 0,2 & 0,6 & 0,2 & $\mathrm{H} 1$ & \\
\hline C.Ing. 18 & {$[5004]$} & 5 & & & $x$ & & & & & & & & & & & & 3,6 & 0,8 & 0,3 & 0,8 & 0,3 & & $x$ \\
\hline C.Ing. 19 & {$[5004]$} & 5 & & & $x$ & & & & & & & & & & & & 3,2 & 0,8 & 0,3 & 0,8 & 0,3 & & $x$ \\
\hline C. Ing. 20 & [5004] & 5 & & & $x$ & & & & & & & & & & & & 5,6 & 0,9 & 0,3 & 0,8 & 0,3 & & $x$ \\
\hline C. Ing. 21 & $5003 / 5004$ & 5 & & & & & $x$ & & & & & & & & & & 4,7 & 0,7 & 0,3 & 0,7 & 0,3 & & $x$ \\
\hline C. Ing. 22 & $5003 / 5004$ & 5 & $x$ & $x$ & $x$ & & & & & 1 & 0,3 & 1,3 & & $x$ & & $x$ & 3 & 1 & 0,3 & 1 & 0,3 & & $x$ \\
\hline C. Ing. 23 & $5005 / 500$ & 5 & & & $x$ & & & & & & & & & & & & 5,4 & 0,9 & 0,2 & 0,8 & 0,2 & & $x$ \\
\hline C. Ing. 24 & $5005 / 500$ & 5 & & & $x$ & & & & & & & & & & & & 8,7 & 1,1 & 0,3 & 0,9 & 0,3 & & $x$ \\
\hline C. Ing. 25 & {$[5021]$} & 5 & & & & $x$ & & & & & & & & & & & 7,1 & 0,9 & 0,3 & 0,7 & 0,3 & & $x$ \\
\hline C. Ing. 26 & {$[5006]$} & 5 & & & & $x$ & & & & & & & & & & & 3,5 & 0,9 & 0,3 & 0,8 & 0,3 & & $x$ \\
\hline C. Ing. 27 & {$[5006]$} & 5 & & & & & $x$ & & & & & & & & & & 3 & 0,8 & 0,3 & 0,7 & 0,3 & & $x$ \\
\hline C. Ing. 28 & {$[5009]$} & 5 & & & $x$ & & & & & & & & & & & & 4,5 & 0,9 & 0,3 & 0,8 & 0,3 & & $x$ \\
\hline C. Ing. 29 & [5009] & 5 & & & & & $x$ & & & & & & & & & & 6,5 & 0,8 & 0,4 & 0,7 & 0,3 & & $x$ \\
\hline C. Ing. 30 & {$[5016]$} & 5 & & & & & $x$ & & & & & & & & & & 4,7 & 0,7 & 0,3 & 0,6 & 0,3 & & $x$ \\
\hline C. Ing. 31 & {$[5042]$} & 5 & & & & & $x$ & & & & & & & & & & 3,3 & 0,8 & 0,3 & 0,7 & 0,3 & & $x$ \\
\hline C. Ing. 32 & {$[3020]$} & & & & $x$ & & & & & & & & & & & & 2,7 & 0,9 & 0,3 & 0,8 & 0,3 & & $x$ \\
\hline C. Ing. 33 & & & & & $x$ & & & & & & & & & & & & 5,3 & 0,9 & 0,3 & 0,8 & 0,3 & & $x$ \\
\hline C. Ing. 34 & & & & & $x$ & & & & & & & & & & & & 5,6 & 0,8 & 0,2 & 0,7 & 0,2 & & $x$ \\
\hline C. Ing. 35 & & & & & $x$ & & & & & & & & & & & & 6,7 & 0,9 & 0,3 & 0,7 & 0,2 & & $x$ \\
\hline
\end{tabular}

Figura 4 - Tabela dos cachimbos cerâmicos da I.A.U. do Convento dos Inglesinhos.

\begin{tabular}{|c|c|c|c|c|c|c|c|c|c|c|c|c|c|c|c|c|c|c|c|c|c|c|c|}
\hline \multirow{4}{*}{ Inv.e } & \multirow{2}{*}{\multicolumn{2}{|c|}{\begin{tabular}{c|c} 
Ind. \\
Contextuais
\end{tabular}}} & \multirow{2}{*}{\multicolumn{6}{|c|}{ Porção }} & \multicolumn{8}{|c|}{ Caract. Fornilho } & \multicolumn{7}{|c|}{ Caract. Haste } \\
\hline & & & & & & & & & \multirow{2}{*}{\multicolumn{4}{|c|}{ Dimensōes }} & \multicolumn{4}{|c|}{ Decoração } & \multicolumn{5}{|c|}{ Dimensões } & \multicolumn{2}{|c|}{ Decoração } \\
\hline & \multirow[b]{2}{*}{ U.E. } & \multirow[b]{2}{*}{ Sond. } & \multirow[b]{2}{*}{ Forn. } & \multirow[b]{2}{*}{ Ped. } & \multicolumn{3}{|c|}{ Haste } & \multirow[b]{2}{*}{ Boq. } & & & & & \multirow[b]{2}{*}{ Sim } & \multirow[b]{2}{*}{ Não } & \multicolumn{2}{|c|}{ Marca de Produtor } & \multirow[b]{2}{*}{ Comp. } & \multirow[b]{2}{*}{$\begin{array}{c}\text { Distal. } \\
\text { Ext. }\end{array}$} & \multirow{2}{*}{$\begin{array}{c}\text { Diâm. } \\
\text { Distal. } \\
\text { Int. }\end{array}$} & \multirow[b]{2}{*}{$\begin{array}{c}\text { Diâm. } \\
\text { Prox. } \\
\text { Ext. }\end{array}$} & \multirow[b]{2}{*}{$\begin{array}{l}\text { Diâm. } \\
\text { Prox. } \\
\text { Int. }\end{array}$} & \multirow[b]{2}{*}{$\operatorname{sim}$} & \multirow[b]{2}{*}{ Não } \\
\hline & & & & & Distal & Mesial & Proxi. & & $\begin{array}{c}\text { Diàm. } \\
\text { For. }\end{array}$ & $\begin{array}{l}\text { Diâm. } \\
\text { Hast. }\end{array}$ & $\begin{array}{c}\text { Diâm. } \\
\text { Orifíi } \\
0\end{array}$ & $\begin{array}{c}\text { Diâm. } \\
\text { Penún } \\
\text { culo }\end{array}$ & & & Sim & Não & & & & & & & \\
\hline P. Mes. 1 & {$[1000]$} & & 1 & & $x$ & & & & & & & & & & & & 3,7 & 0,7 & 0,2 & 0,6 & 0,2 & & $x$ \\
\hline P. Mes. 2 & [1062] & $\begin{array}{c}\text { Área } \\
1\end{array}$ & & & $\mathrm{x}$ & & & & & & & & & & & & 5 & 0,9 & 0,3 & 0,9 & 0,2 & H2 & \\
\hline P. Mes. 3 & [2002] & $\begin{array}{l}\text { Área } \\
\text { S/so }\end{array}$ & & & $x$ & & & & & & & & & & & & 6,9 & 1,1 & 0,3 & 0,9 & 0,3 & H3 & \\
\hline P. Mes. 4 & [2033] & & & & & & $\mathrm{x}$ & & & & & & & & & & 4,2 & 0,5 & 0,2 & 0,5 & 0,2 & & $x$ \\
\hline P. Mes. 5 & [2033] & & & & & $x$ & & & & & & & & & & & 2,1 & 0,7 & 0,2 & 0,7 & 0,2 & & $x$ \\
\hline P. Mes. 6 & [2033] & & & & $x$ & & & & & & & & & & & & 2,3 & 1,1 & 0,2 & 1,1 & 0,2 & & \\
\hline P. Mes. 7 & [2033] & & & & $x$ & & & & & & & & & & & & 5,5 & 0,8 & 0,2 & 0,8 & 0,2 & & $x$ \\
\hline P. Mes. 8 & [2036] & & & & $\mathrm{x}$ & & & & & & & & & & & & 5,2 & 0,9 & 0,2 & 0,7 & 0,2 & & $x$ \\
\hline P. Mes. 9 & [2038] & & & & & & $x$ & & & & & & & & & & 3,3 & 0,7 & 0,2 & 0,6 & 0,2 & & $x$ \\
\hline P. Mes. 10 & [2045] & & & & & & $x$ & & & & & & & & & & 5 & 0,8 & 0,3 & 0,6 & 0,2 & & $x$ \\
\hline P. Mes. 11 & [2045] & & & & $x$ & & & & & & & & & & & & 4,6 & 1 & 0,3 & 1 & 0,3 & $\mathrm{H} 4$ & \\
\hline P. Mes. 12 & [2058] & & & & $x$ & & & & & & & & & & & & 5,2 & 1,2 & 0,4 & 0,9 & 0,3 & & $x$ \\
\hline P. Mes. 13 & [2065] & & & $x$ & & & & & 1,4 & 0,9 & 0,3 & 1,1 & B1 & & "RB" & & & & & & & & \\
\hline P. Mes. 14 & [2102] & & & & $x$ & & & & & & & & & & & & 4,4 & 1,1 & 0,4 & 0,9 & 0,3 & & $x$ \\
\hline P. Mes. 15 & {$[4000]$} & $\begin{array}{c}\text { Área } \\
4\end{array}$ & & $\mathrm{x}$ & & & $\mathrm{x}$ & & & 0,7 & 1,2 & & & $\mathrm{x}$ & & $\mathrm{x}$ & 2,5 & & & & & & $\mathrm{x}$ \\
\hline P. Mes. 16 & [4010] & $\begin{array}{c}\text { Área } \\
4\end{array}$ & & & $\mathrm{x}$ & & & & & & & & & & & & 3,3 & 1 & 0,4 & 0,9 & 0,3 & & $\mathrm{x}$ \\
\hline P. Mes. 17 & [4027] & & & $x$ & & & $x$ & & 1,9 & 1,2 & 0,2 & & & $x$ & & $x$ & & 3,9 & & & & & \\
\hline
\end{tabular}

Figura 5-Tabela dos cachimbos cerâmicos da I.A.U. do Palácio Mesquitela. 


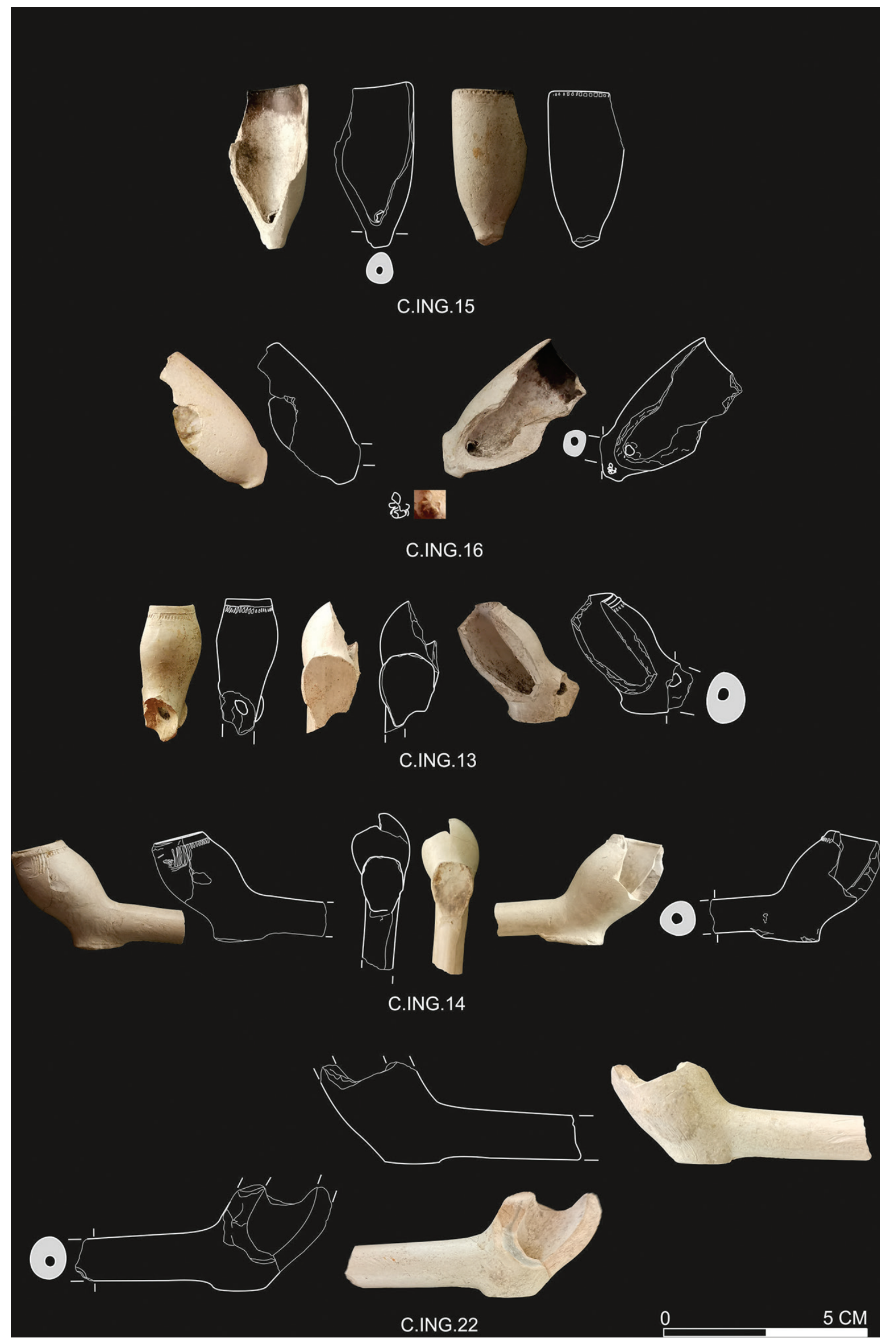

Figura 6 - "Convento dos Inglesinhos": fragmentos preservando o fornilho. 


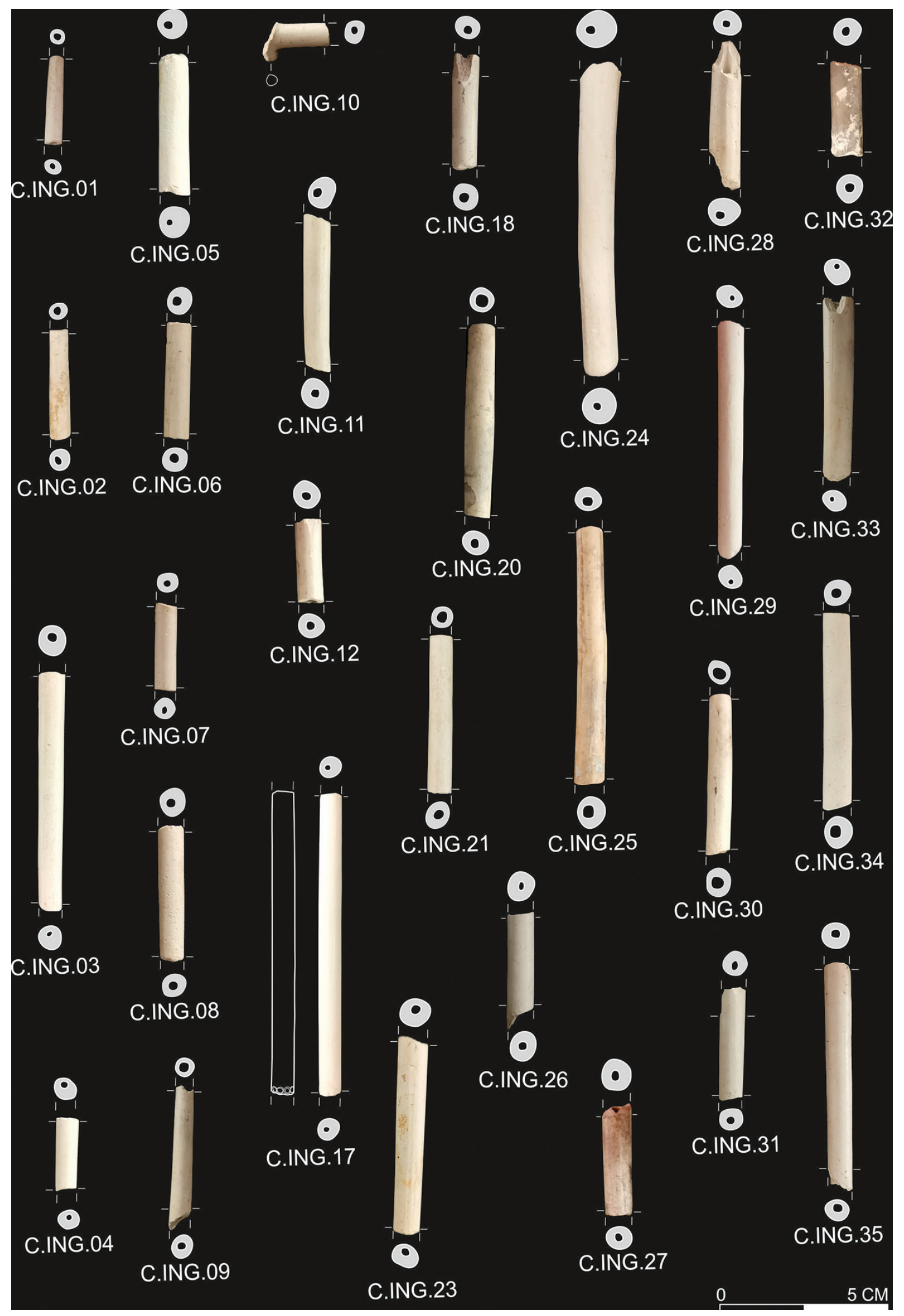

Figura 7 - "Convento dos Inglesinhos”: fragmentos de haste. 


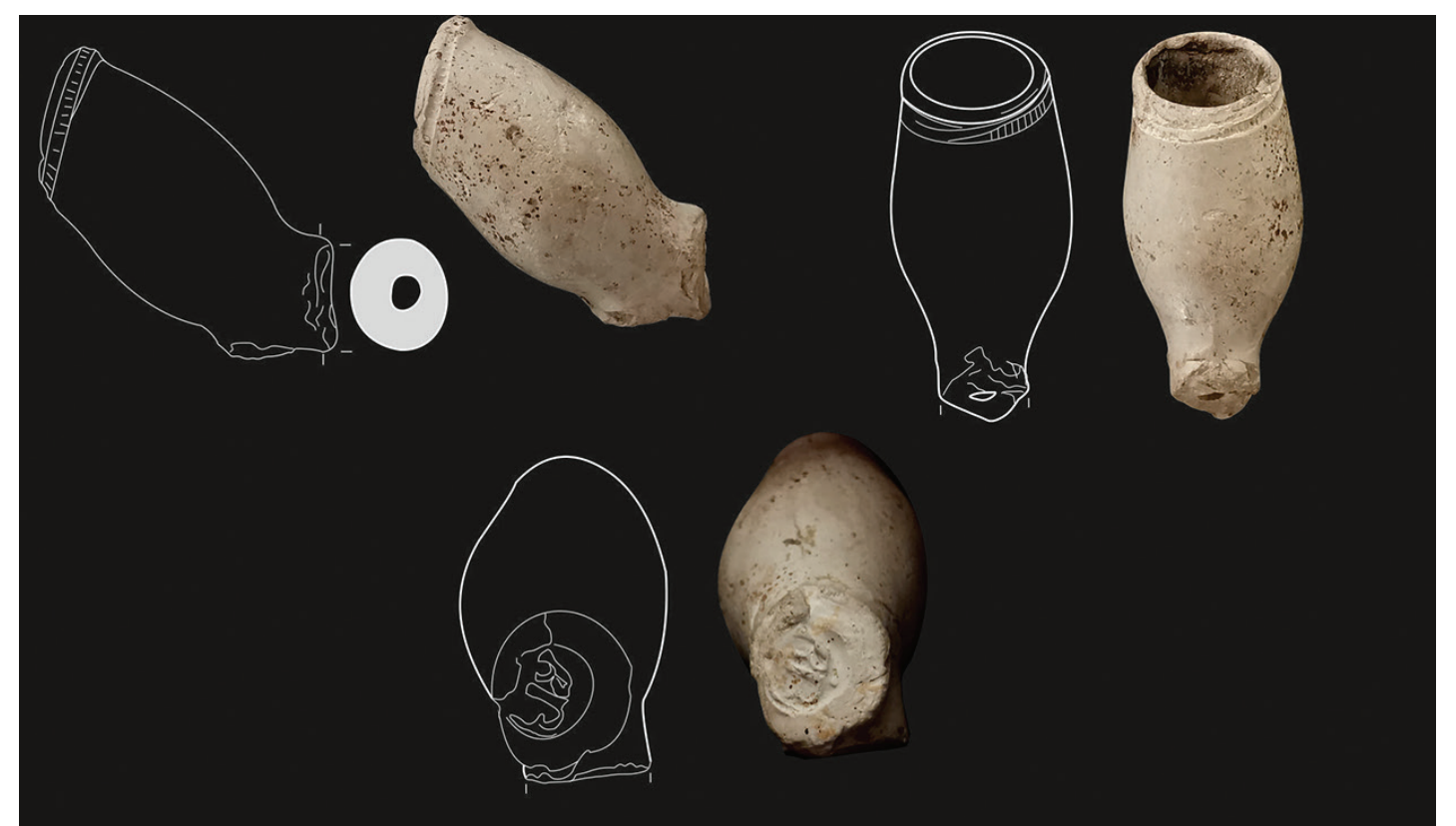

P.MES.13

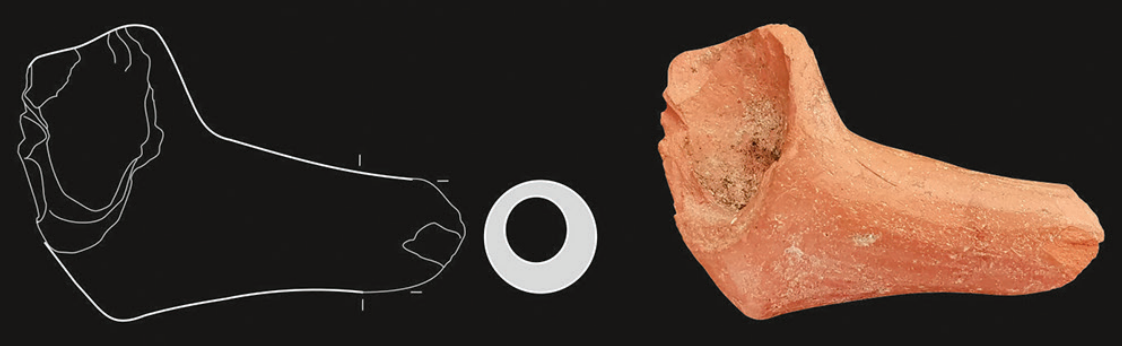

P.MES. 15
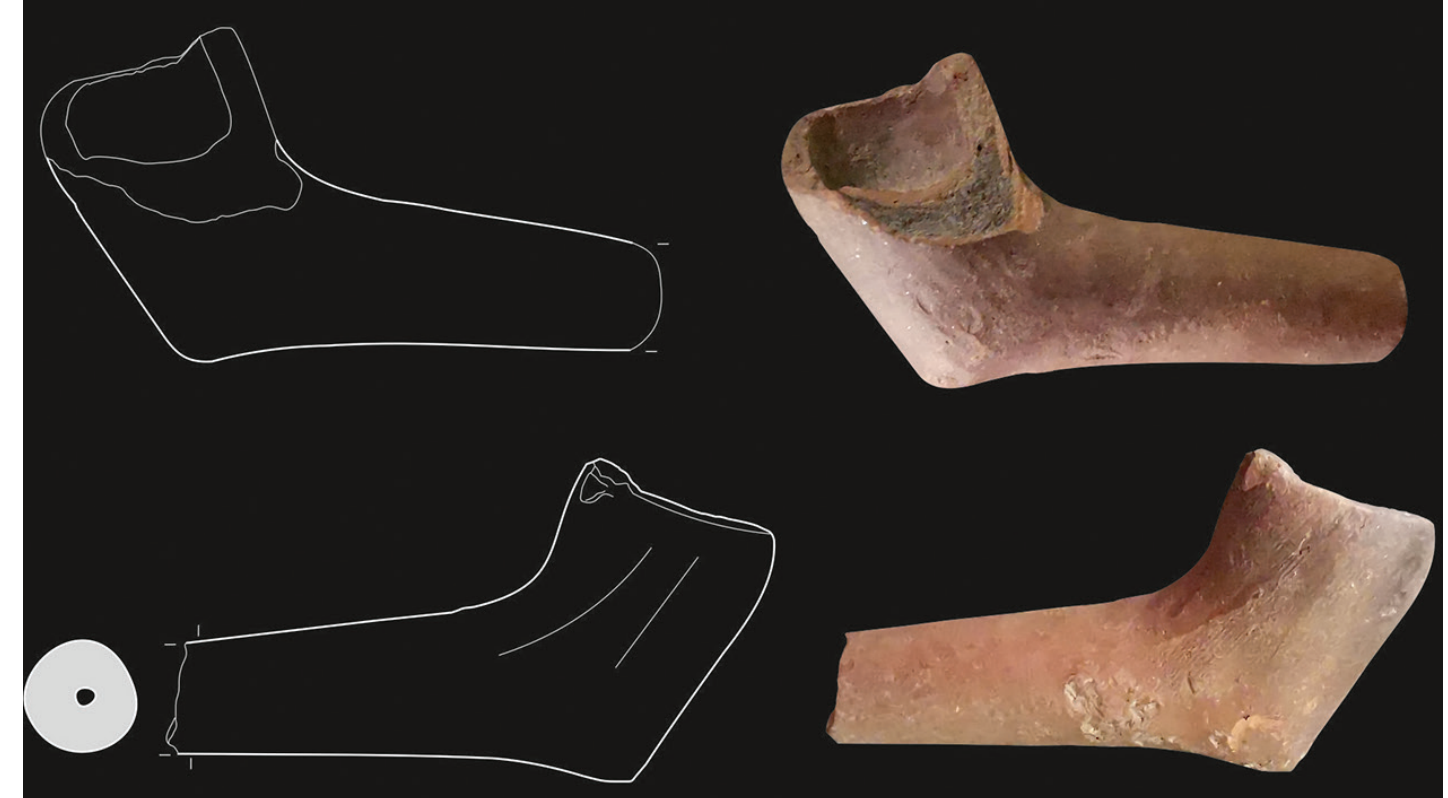

P.MES.17

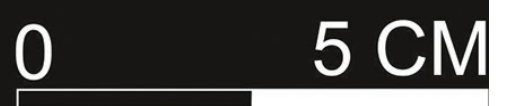

Figura 8 - Palácio Mesquitela: fragmentos preservando o fornilho. 


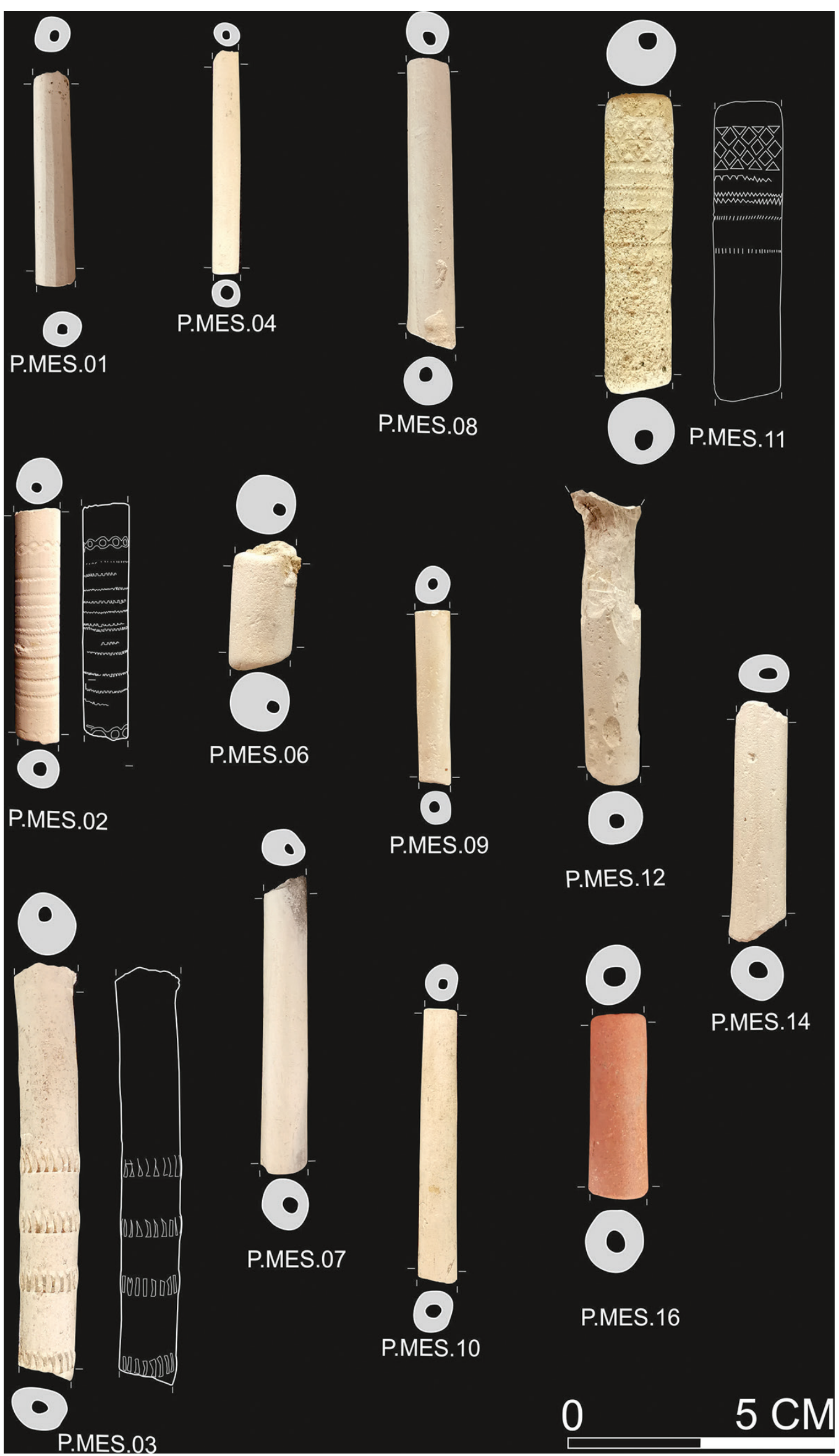

Figura 9-Palácio Mesquitela: fragmentos de haste. 


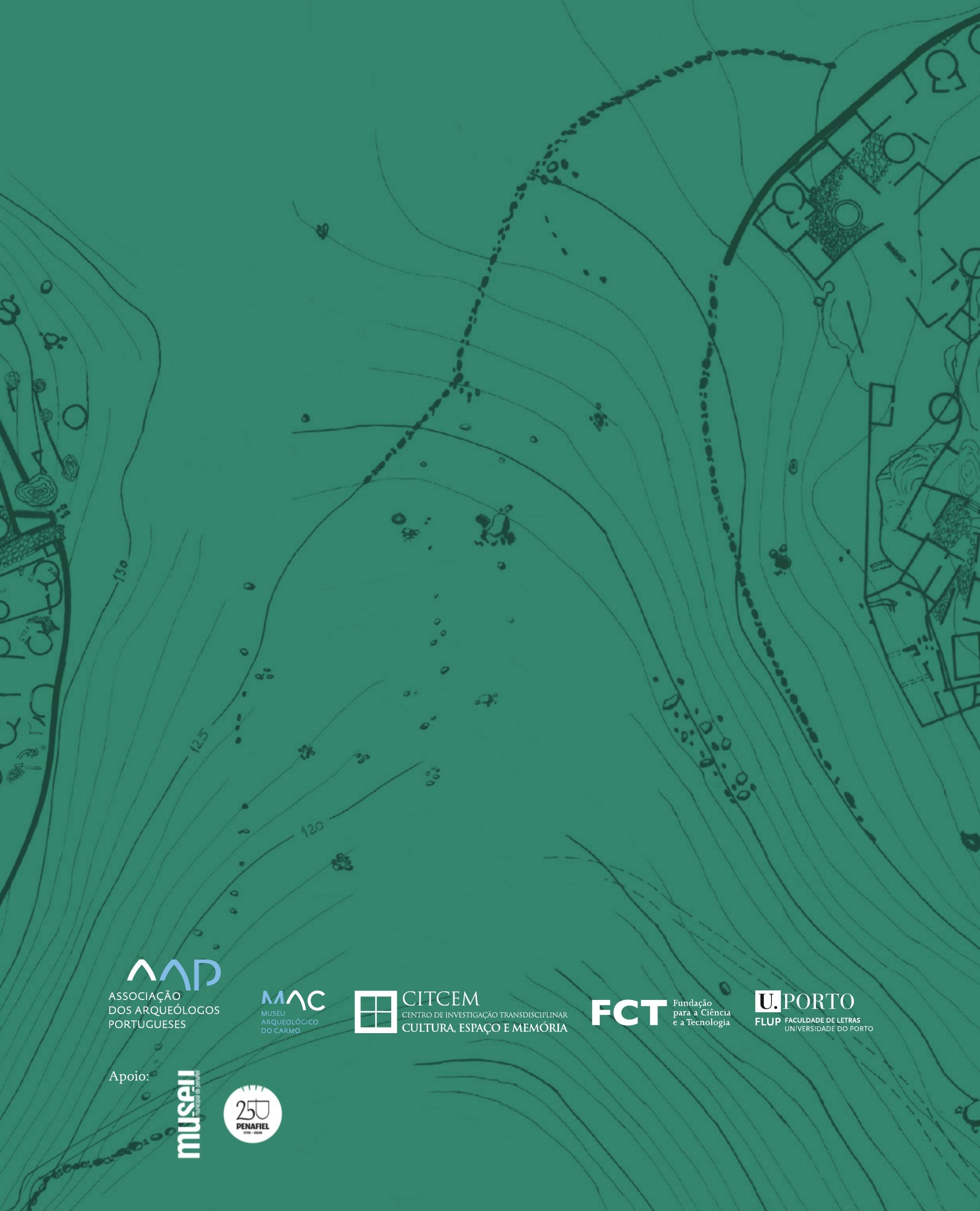

